Research Article

\title{
Experimental Study on 3D Roughness and Shear Failure Mechanism of Rock Mass Discontinuity
}

\author{
Jihong Wei (iD, Yan Men, Shaorui Sun (iD, Huilin Le, and Feng Zhu \\ School of Earth Science and Engineering, Hohai University, Nanjing 210098, China \\ Correspondence should be addressed to Shaorui Sun; ssrfish@hhu.edu.cn
}

Received 15 December 2017; Accepted 11 February 2018; Published 1 April 2018

Academic Editor: Xiang Fan

Copyright (C) 2018 Jihong Wei et al. This is an open access article distributed under the Creative Commons Attribution License, which permits unrestricted use, distribution, and reproduction in any medium, provided the original work is properly cited.

\begin{abstract}
A set of systematic experimental methods, including 3D accuracy scanning and identification of discontinuous surface topography, physical model construction, and laboratory direct shear experiment under different directions and normal stresses, was proposed to research the influence of discontinuity roughness on strength and deformation of discontinuity. During physical model construction of discontinuity, three types of discontinuity and rough natural rock joint surface models were constructed and moulded. Meanwhile, many influence factors of discontinuity surface topography, such as asperity inclination angle (AIA), asperity height (AH), normal stress (NS), and shear direction (SD), were considered during the direct shear experiment. On the basis of the experimental results, it can be found that there were two types of failure modes under different loading conditions, which were named "failure by shearing through the asperities" and "failure by sliding over the asperities". The obvious stress concentration phenomenon, climbing, and cutting effects appeared in the process of the direct shear experiment. In addition, the accurate identification of surface topography of natural rough rock joint surface was carried out using three-dimensional sensing system (3DSS) and self-programming software before and after the experiment. The subsamples with the same surface topography as the original samples were moulded using a selfdeveloped instrument. Then, the mechanical behavior of the original samples and subsamples for the natural rough rock joint surface under different shear directions and normal stresses was studied. The results show that the shear displacement under different shear directions and normal stresses is very large before it reaches the failure state. And the residual strength of the original samples is higher than that of the subsamples. In addition, failure modes of the subsamples are main failure by shearing through the asperities due to the significant difference between peak shear strength and residual strength. The failure modes for parts of the original samples are failure by sliding over the asperities. The change ratio of area for the discontinuity after the experiment depends on surface topography, strength of heave on the surface of discontinuity, and particle size of minerals on the surface of discontinuity.
\end{abstract}

\section{Introduction}

Rock mass discontinuity plays a major role in the deformation and failure of rock mass projects. The destruction of many rock engineering projects is related to the strength of rock mass discontinuity. In the past research, discontinuity is often assumed as a smooth and straight plane without considering the characteristics of its uneven surface, leading to underestimation of its shear strength. The natural roughness of rock mass discontinuity has the characteristics of anisotropy and nonhomogeneity, particularly the anisotropy that has an impact on the shear strength of discontinuity. However, shear strength of discontinuity may be overestimated considering the surface character of discontinuity. For example, Barton's JRC-JCS shear strength criterion is found that it sometimes tends to overestimate the shear strength of natural joints with less matched surfaces [1]. Therefore, research on the shear strength of discontinuity concerning its surface topography is very significant during stability analysis and evaluation of rock mass engineering.

The characteristics of discontinuity, which are closely related to the failure behavior of rock mass, are often studied from the angle of strength and deformation. Many experimental and theoretical researches show that mechanical properties of discontinuity are related not only to the components and texture of rock mass and discontinuous combination characterizations but also to the roughness of discontinuity which is a main factor affecting strength and deformation of discontinuity [2-4]. The two parameters joint 
roughness coefficient (JRC) and joint matching coefficient (JMC) are often used to characterize discontinuity. In order to study the relationship between strength or deformation and surface topography of discontinuity, the identification of surface characteristics of discontinuity is vital. At present, the way of measuring surface topography is mainly based on mechanical and optical methods. Kulatilake et al. [5] have used the line scaling method, variogram method, spectral method, and roughness-length method to accurately measure joint surface roughness. Develi et al. [6] have used a new device to measure surface topography of discontinuity. Feng et al. [7] and Fardin et al. [8] have researched rock joint surface roughness using noncontact measurement techniques in the field. Compared with the mechanical method, the optical method is widely used to identify uneven surface due to its noncontact measurement which has some advantages such as high precision and nondestructive testing. In the aspects of assessment of joint roughness, some works [9-14] were conducted from the angle of fractal geometry. In these works, assessment and estimation of joint roughness are carried out based on the relationship between fractal dimension and surface topography of discontinuity. In addition, many researchers [15-19] have adopted different methodologies to assess or estimate joint roughness from the angle of quantity. The strength theories of discontinuity have been studied by many researchers. Barton [20] has conducted a number of research works and proposed an experiential formula considering the relationship between climbing or shear dilation and normal stress. And this formula is usually used under lower normal stress. Grasselli et al. [21] have proposed the Grasselli model which considers 3D roughness on the surface of discontinuity using a number of optical tests and direct shear tests. Riquelme et al. [22] have carried out the discontinuity spacing analysis in rock mass using $3 \mathrm{D}$ point clouds. Concerning the anisotropy of discontinuity, Koyama et al. [23] have analyzed the change process of surface wearing of discontinuity in the process of the direct shear experiment and numerical simulation. Jiang et al. [24] have studied the relationship between surface roughness and mechanical properties of rock joints.

Previous studies have shown that most of the past relevant studies lack systematic experimental research. And, interpretation of the mechanisms of discontinuity failure with different roughness degrees has not been conducted, for example, shear failure under different loading, failure of heave on the surface of discontinuity, influence of microstructure topography on macroshear strength, and so on. In order to research the influence of anisotropy and surface topography of discontinuity on shear strength, four different models such as roughness type I model, roughness type II model, roughness type III model, and natural rough rock joint surface model were used to study mechanical behavior and the shear failure mechanism of discontinuity under different normal stresses and shear directions.

\section{Materials and Experimental Methods}

Because of the complexity of surface topography and poor repeatability for discontinuity experiment, discontinuity is often constructed by some rock-like materials, such as concrete, gypsum, and so on. In order to research the influence of surface topography on strength and deformation of discontinuity, some influence factors such as asperity inclination angle, asperity height, and asperity shape are considered in the process of mould construction. According to these influence factors, roughness type I model, roughness type II model, roughness type III model, and natural rough rock joint surface model were constructed so as to research failure mechanism of discontinuity under different normal stresses and shear directions, particularly for the effect of anisotropy on strength of discontinuity.

\subsection{Mould Design}

\subsubsection{Roughness Type I, Roughness Type II, and Roughness Type III Models}

(1) Design of Mould Patterns. In the process of mould design, four types of asperity inclination angles and asperity heights are considered. The size of steel mould is $300 \times 200 \times 100 \mathrm{~mm}$, and its error (precision) is $<0.1 \mathrm{~mm}$. The asperity inclination angles include $10^{\circ}, 20^{\circ}, 30^{\circ}$, and $45^{\circ}$, respectively. The asperity heights include $2 \mathrm{~mm}, 3 \mathrm{~mm}, 4 \mathrm{~mm}$, and $5 \mathrm{~mm}$, respectively. The roughness type I and roughness type II models belong to similar types of model. The shape of discontinuity for roughness type III model is designed with a combination of two continuous and different asperity heights. The types of combinations include 5-2 mm, 5-3 mm, 5-4 mm, and 5-5 mm. Four moulds for three types of models are manufactured according to different angles or different asperity heights. Figure 1 shows parts of the basic shapes of three types of models.

(2) Sample Preparation. For natural rock mass discontinuity, the heaves on the surface of discontinuity have the same strength with rock mass under the condition of nonfilling. However, it is very difficult to guarantee that there is only a small difference in strength for the heaves and rock mass. Therefore, in order to decrease the differences for heaves and rock mass, selection of the materials, such as sand, cement, water, epoxy, and binder, is very vital. To avoid significant difference in the mechanical properties for both of them, the particle size of sand is controlled between $0.25 \mathrm{~mm}$ and $0.35 \mathrm{~mm}$. The cement and other materials have the same type. Meanwhile, to decrease difference among mould samples, all samples in this experiment are constructed by using the same mould, same mix proportion, and same curing condition and period. The cement is ordinary Portland cement with number $42.5 \mathrm{R}$, and the water cement ratio is 0.45 and the curing period is $28-30$ days under moist conditions. The precast samples are processed into experimental samples with the diameter being $50 \mathrm{~mm}$ and height being $50 \mathrm{~mm}$. All experimental samples must meet the requirement that the inclination error for the top and bottom surface of the sample is $<3^{\circ}$. Figure 2 shows three different types of precast samples with different types of models and one original sample with even shear face which is used to conduct experiments concerning epoxy and binder. 

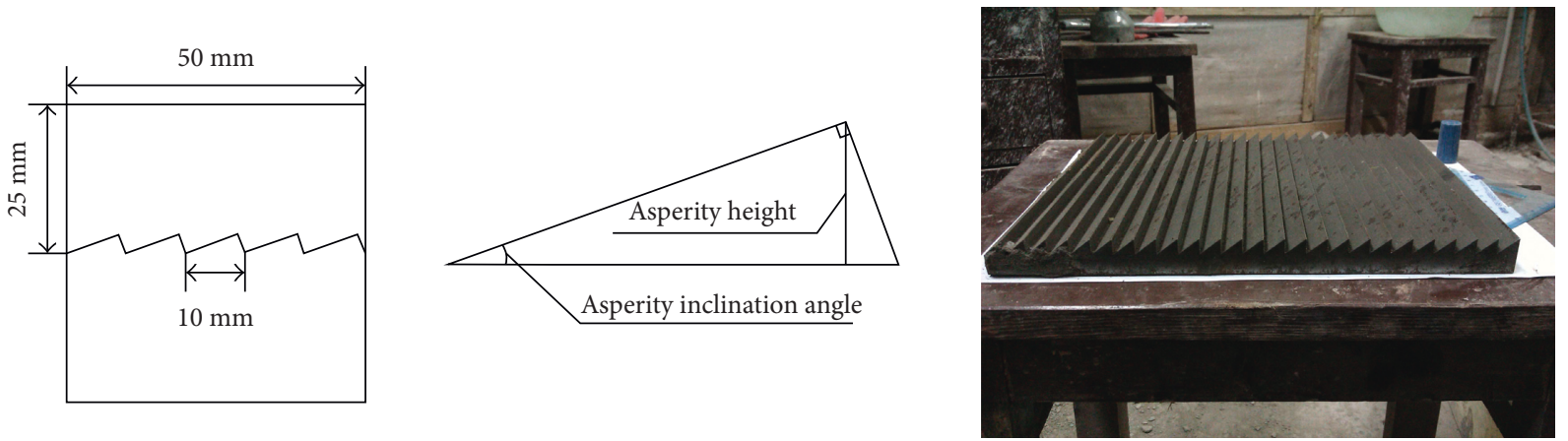

(a)
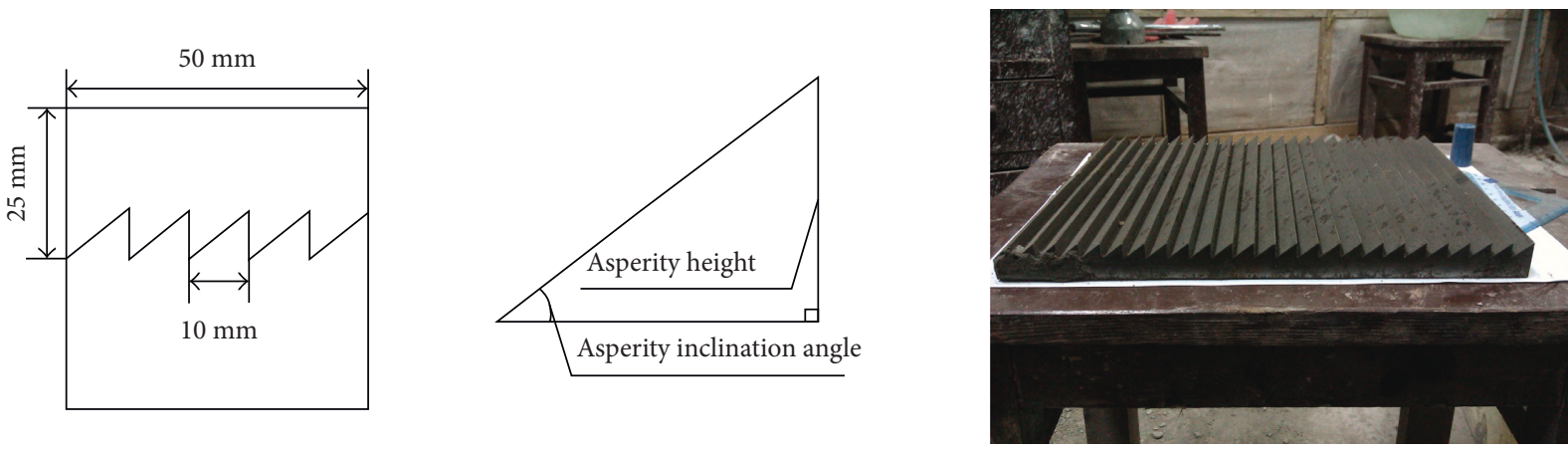

(b)
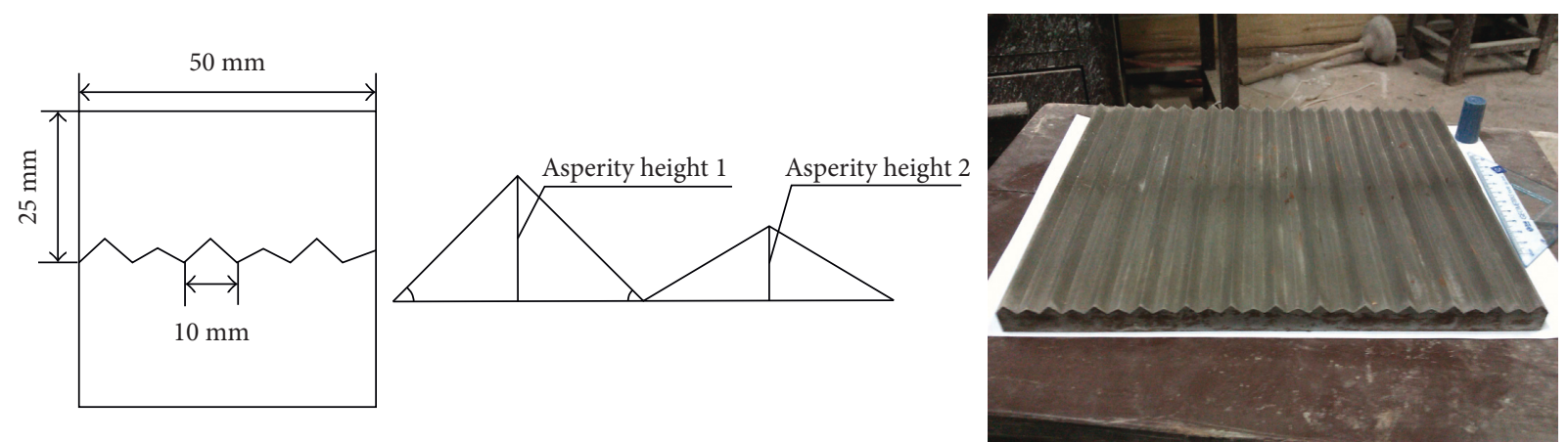

(c)

FIgUre 1: Roughness types. (a) Roughness type I model; (b) roughness type II model; (c) roughness type III model.

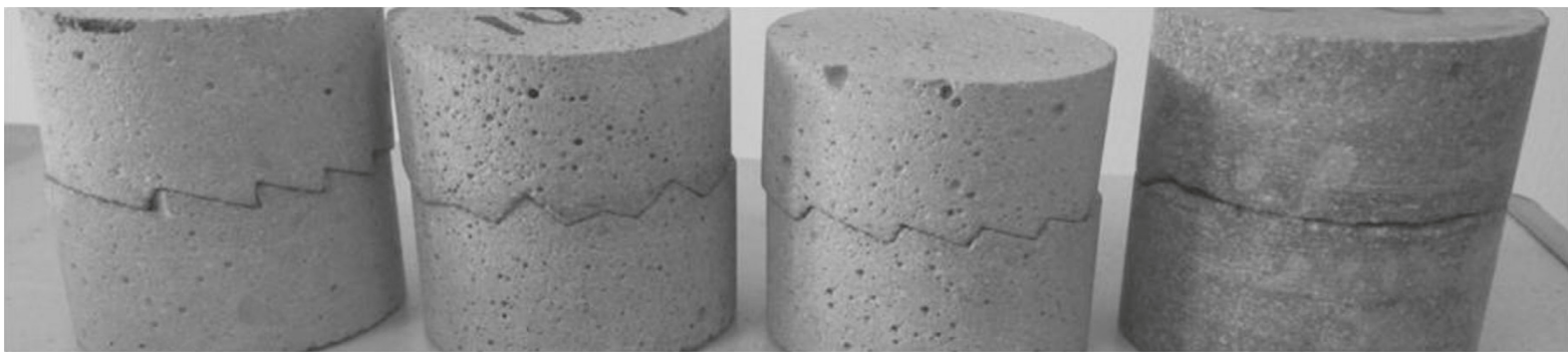

(a)

(b)

(c)

(d)

FIGURE 2: The precast model with different types of discontinuity and natural rough rock joint surface model. (a) Roughness type I model; (b) roughness type II model; (c) roughness type III model; (d) natural rough rock joint surface model. 


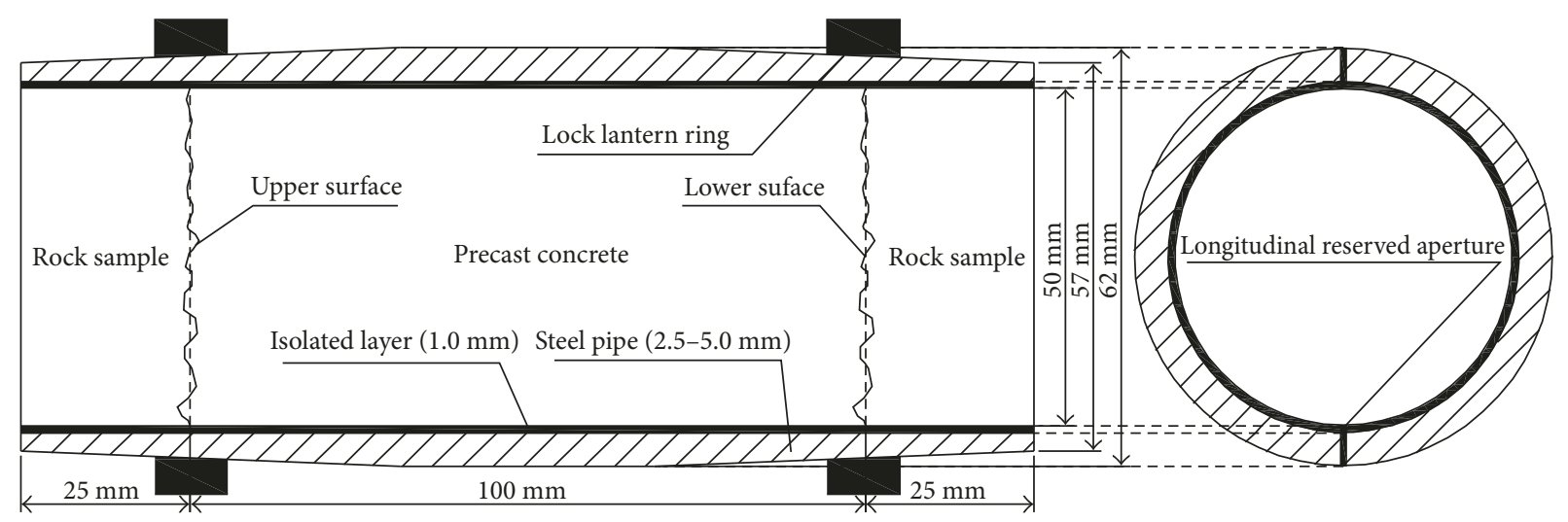

FIGURE 3: Structure of the mould for the natural rough rock joint surface model.

\subsubsection{Natural Rough Rock Joint Surface Model}

(1) Design of Mould Patterns. When the anisotropy of discontinuity is researched, the direct shear experiment will be conducted from five different shear directions. An original sample cannot meet the requirement of shear experiments. Therefore, many subsamples which have the same roughness as the original samples need to be remoulded. In order to guarantee the precision of the subsamples, a mould, which is used to remould the subsamples based on the original samples, is designed. Figure 3 shows the structure of the mould. It can be found from Figure 3 that the inner diameter of the mould is $50 \mathrm{~mm}$. Two parts of the original sample are placed separately at the both ends of the device. The length of the precast sample is about $100 \mathrm{~mm}$, which will be cut into two parts and the length of every parts is about $25 \mathrm{~mm}$. The isolated layer is placed between the steel mould and sample in order to avoid bonding of the concrete and steel mould. Two lock lantern rings are placed outside the steel mould so as to lock tightly two parts of separate steel moulds when the precast of the sample has been finished.

(2) Sample Preparation. Some rock cores with diameter being $72 \mathrm{~mm}$ are obtained from the Lukou airport station of the Nanjing subway. The lithology of the original samples for the natural rough rock joint surface model is andesite. The physical-mechanical properties of sites are similar to the concrete. Eight original samples (no. A1 to A8) with diameter being $50 \mathrm{~mm}$ and height being $50 \mathrm{~mm}$ are prepared by drilling, cutting, and wearing methods based on the rock cores with diameter being $72 \mathrm{~mm}$. The surface topography of every original sample was scanned using a new noncontact device named "three-dimensional sensing system" (3DSS). The scanning and identification of discontinuity can be seen from Figure 4.

The 3DSS can scan complex surface topography of every object from the angle of three dimensions by using the optical technique, computer digital imaging technique, and phase measurement technique. Many digital images will be projected on the object when the grating projection device begins to scan. Two vidicons will simultaneously collect the corresponding image and then decode and calculate the phase of the image. Three-dimensional coordination of the public zone for the collected image will be calculated utilizing matching technique and triangular scanning principal. The accuracy of scanning can reach $0.03 \mathrm{~mm}$, which can completely meet the requirement of accuracy identification of discontinuity.

The scanning of discontinuous surface topography can be divided into two phases, which are before and after the experiment, so as to compare and identify roughness changes of the original samples. In order to analyze quantificationally the area changes before and after the experiment, accuracy identification and reconstruction of surface topography become a necessary process. According to the scanning results of different discontinuity surface topography, a computer program based on the Delaunay triangular mesh subdivision method are compiled in this paper and used to calculate the surface areas of different discontinuities. Figure 5 shows the reconstruction map utilizing the computer program based on the scanning results of discontinuity surface topography.

For reconstruction of the subsamples, the mould shown in Figure 3 is used. First, butter is applied uniformly in the wall of the steel tube, and wax paper is usedto cover the butter. Second, the lower sample is placed at the bottom of the steel tube and is locked using lantern ring. Thirdly, precast concrete which has the same requirement with roughness type I model, roughness type II model, and roughness type III model are poured in the steel tube. The thickness of concrete in the steel tube is about $100 \mathrm{~mm}$. Finally, the upper sample in the steel tube is closed to the precast concrete with some pressure, and then the next lantern ring is use to lock the steel tube. To avoid nonuniformity of the concrete in the steel tube, the sample will be turned upside down before solidification and is placed horizontally during curing period. After curing period, concrete samples will be taken out from the mould. The discontinuity face should be cleaned completely before it is used to manufacture the next sample. The surface topography should not be damaged during the process of cleaning. Eight sets of the subsamples with diameter being $50 \mathrm{~mm}$ and height being $50 \mathrm{~mm}$ are prepared by the same manufacturing method. Figure 6(a) shows the comparison between the original samples and subsamples, and Figure 6(b) shows eight sets of the subsamples for natural rough rock joint surfaces. On the basis of Figure 6(a), it can 


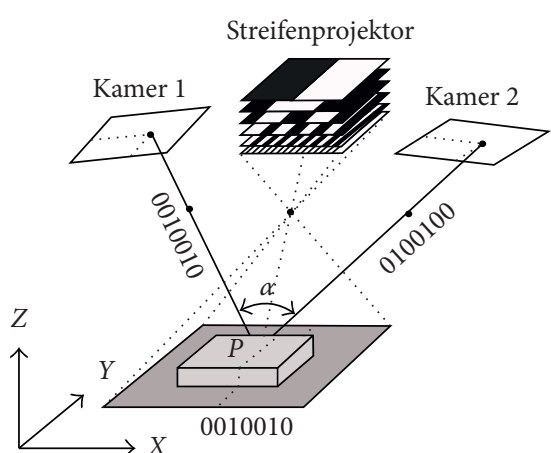

(a)

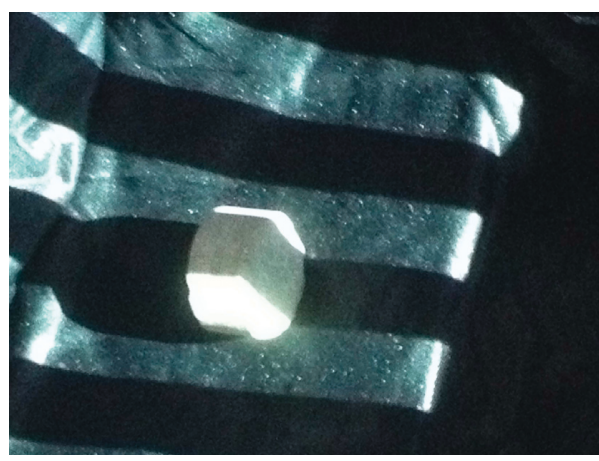

(c)

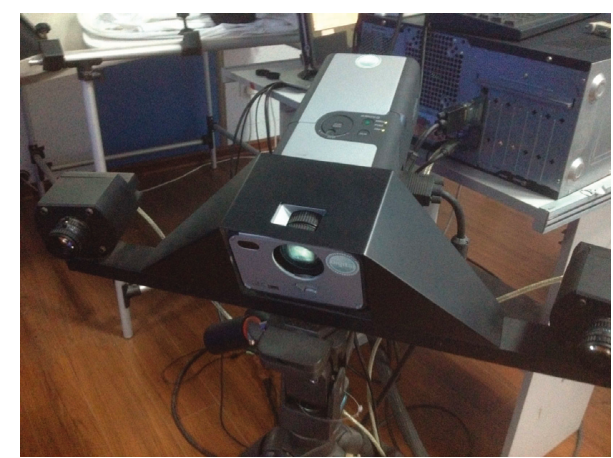

(b)

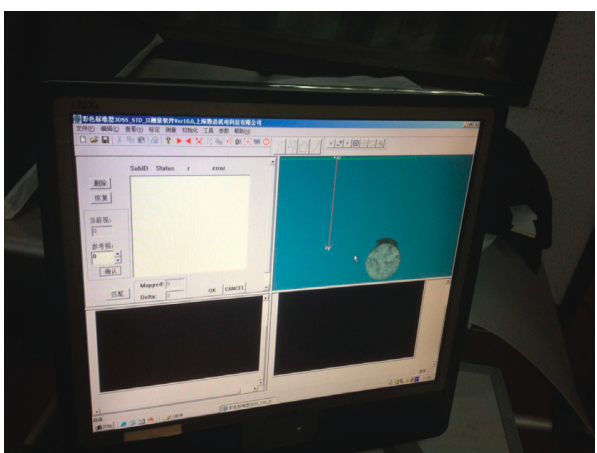

(d)

FIGURE 4: Scanning and identification of the original samples using the 3DSS device. (a) Principal of scanning; (b) equipment of scanning (3DSS); (c) rock sample; (d) postprocessing system.

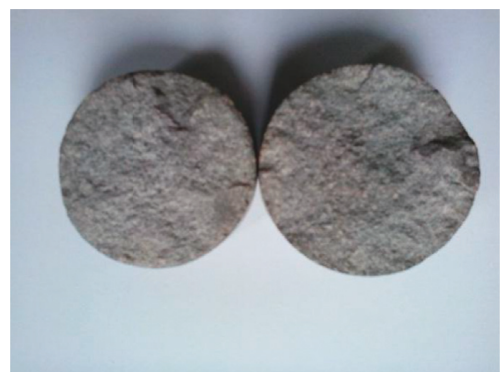

(a)

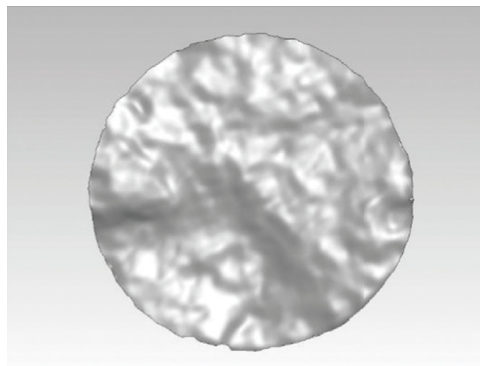

(b)

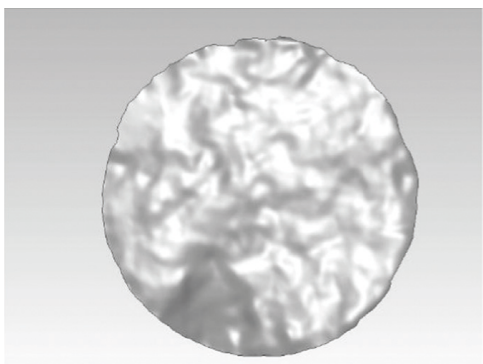

(c)

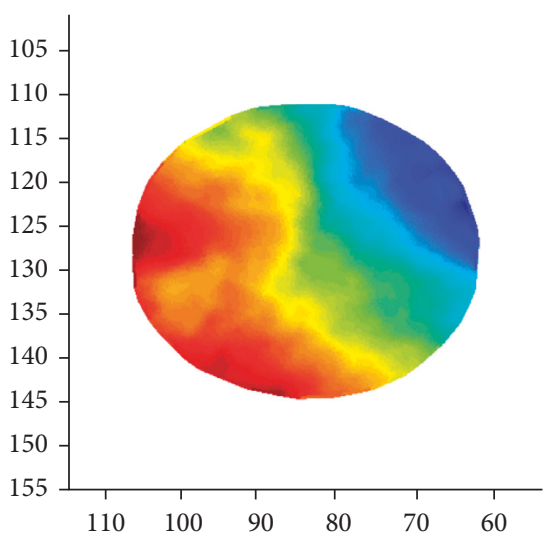

(d)

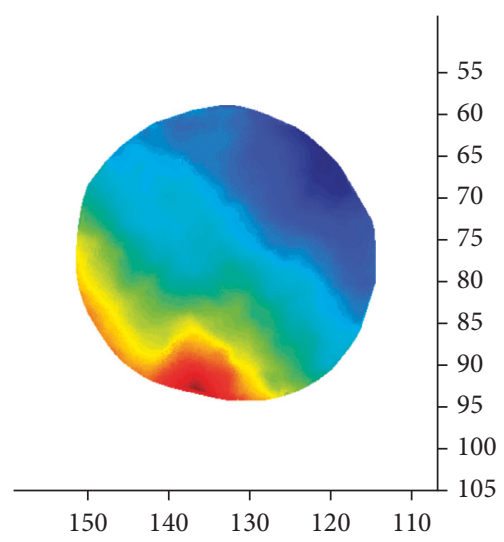

(e)

FIGURE 5: Reconstruction of surface topography of discontinuity for the natural rough rock joint surface model (sample B5). (a) Sample No. B5; (b) preprocess of the upper surface; (c) preprocess of the lower surface; (d) 3D reconstruction of the upper surface; (e) 3D reconstruction of the lower surface. 


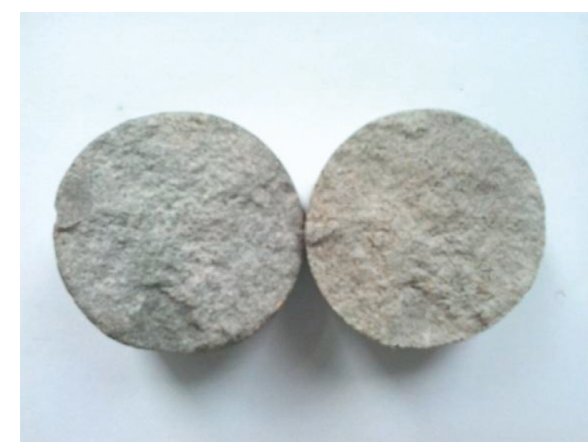

(a)

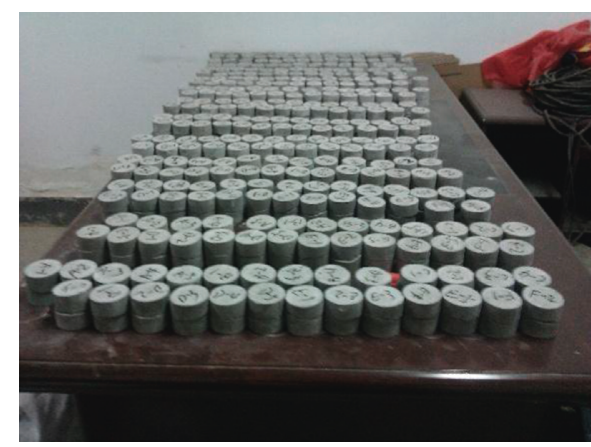

(b)

Figure 6: Subsamples of natural rough rock joint surfaces. (a) Comparison between original samples and subsamples; (b) parts of subsamples.

be found that the uniformity between the original sample and subsample is very good. It indicates that the method used to remould the subsamples is appropriate for this experiment.

2.2. Experimental Procedures. The direct shear experiment is used for roughness type I, roughness type II, and roughness type III models. Aiming at roughness type I, roughness type II, and roughness type III models, four normal stresses with value being $0.51 \mathrm{MPa}, 1.02 \mathrm{MPa}, 2.04 \mathrm{MPa}$, and $3.06 \mathrm{MPa}$ and four shear directions with value being $10^{\circ}, 20^{\circ}, 30^{\circ}$, and $45^{\circ}$ are considered in the process of the direct shear experiment. For the natural rough rock joint surface model, three normal stresses with value being $0.51 \mathrm{MPa}, 1.02 \mathrm{MPa}$, and $2.04 \mathrm{MPa}$ and four shear directions with value being $0^{\circ}, 10^{\circ}, 20^{\circ}$, and $30^{\circ}$ are considered in the process of the experiment. Figure 7 shows the definition method of shear direction. follows:

Procedures of the direct shear experiment are listed as

(1) Confirmation of the area of shear surface: the diameter and height of the sample are measured and recorded. At the same time, surface topography of discontinuity is taken photo and described.

(2) Inspection of the direct shear instrument: in order to guarantee veracity of experimental results, all parts of direct shear instrument will be inspected before the experiment. Meanwhile, trial experiment must be conducted by using a standard sample.

(3) Layout of the sample: due to consideration of anisotropy of discontinuity, every sample will be marked a remarkable line at the lateral of the sample which is used to define shear direction. Initial normal stress will be exerted on the sample.

(4) Layout of the displacement measurement instrument: in order to measure an accurate displacement, three measurement instruments will be placed on the normal direction and shear direction, respectively.

(5) Loading method: under condition of certain normal pressure, shear stress will be applied with a loading speed of $0.5-1.0 \mathrm{kN}$ per second and $10-$ 15-step loading. Vertical deformation, horizontal

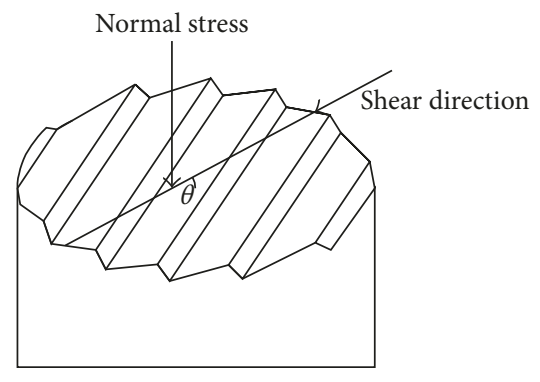

FIgURE 7: Shear direction of discontinuity.

displacement, and shear force will be obtained when the deformation of the sample tends to be in a stable state for every grade load.

(6) ASTM criterion: three to five samples in each group were tested to obtain the average value.

(7) Recording and saving of data: the sample will be taken out from shear box, and failure surface will be taken photo and described.

\section{Analysis on Experimental Results}

3.1. Failure Modes and Analysis on Influence Factors of Discontinuity. Failure modes of rock mass are mainly fracture along discontinuity due to its anisotropy and nonhomogeneity. Based on the curves of shear stress and shear displacement (Figure 8), it can be found that there are two types of failure models generally. One is failure by sliding over the asperities in which the discontinuity with jagged shape is not completely cut off from the bottom of heave and its failure is along the top section of heave, the other is failure by shearing through the asperities in which the heave on the surface of discontinuity is cut off from the bottom section of the heave and its failure surface presents an approximate plane.

According to Figure 8, when the normal stress and roughness degree of discontinuity are quite significant, the failure mode of discontinuity mainly presents failure by shearing through the asperities in which the curve of shear strength and shear displacement will present a peak point and then decrease and present a residual stage. The curve of shear failure is divided into three stages, such as climbing 


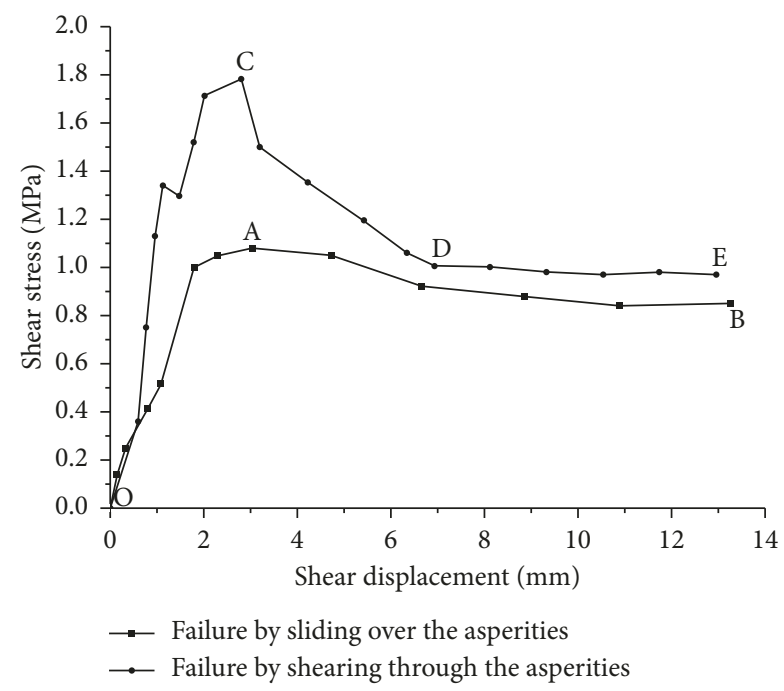

Figure 8: The curve of two failure modes of discontinuity.
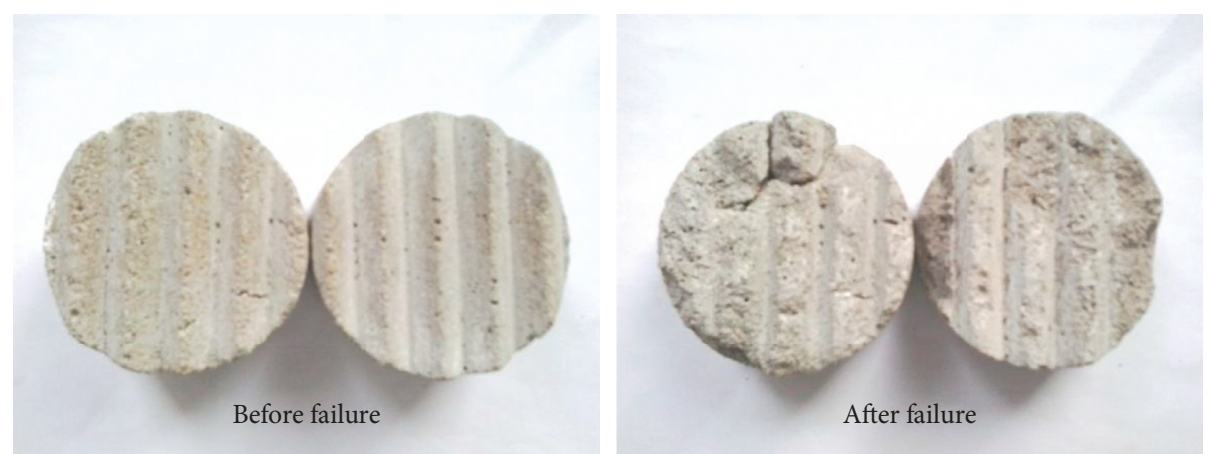

(a)
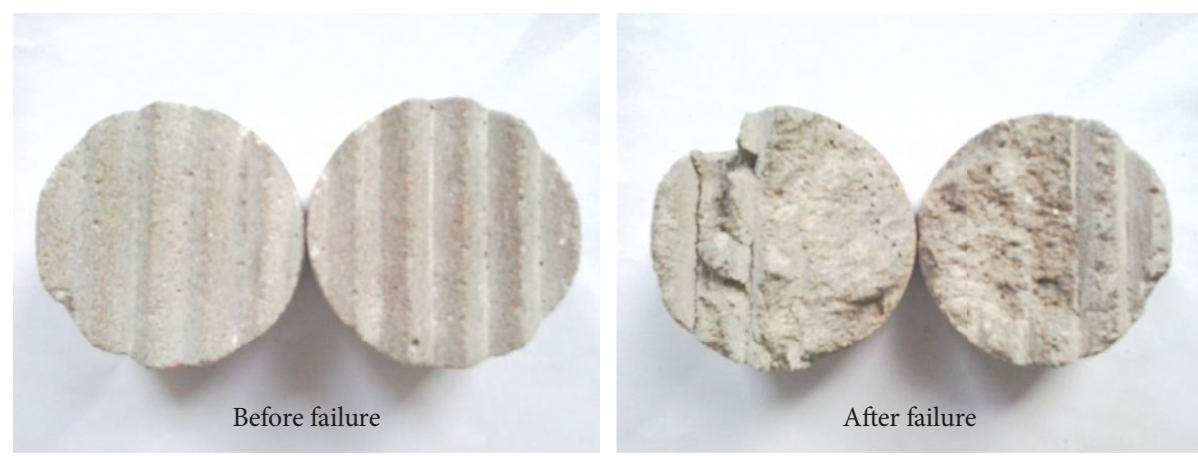

(b)

FIGURE 9: Failure modes of discontinuities based on laboratory experimental results. (a) Failure by sliding over the asperities; (b) failure by shearing through the asperities.

stage (OC), cutting stage (CD), and sliding stage (DE). The curve of failure by sliding over the asperities is divided into two stages, such as climbing stage (OA) and sliding stage (AB). Therefore, based on the typical curves of shear strength and shear displacement for two failure modes, the failure of discontinuity presents brittle character when the heaves on the surface of discontinuity are completely cut off from their bottoms, while it presents ductile character when the roughness of discontinuity is decreased due to the shear process.
Through observing the failure surface of different types of discontinuity after the laboratory experiment under different loading, it can be found that parts of the surface which is at the rear location along the shear direction are very easy to damage compared with the front one of discontinuity (Figure 9).

Most of samples present similar failure characteristics. In addition to the reason which failure mode is related to the strength, surface topography, normal stress, and shear direction of discontinuity, a dominant reason is the own 


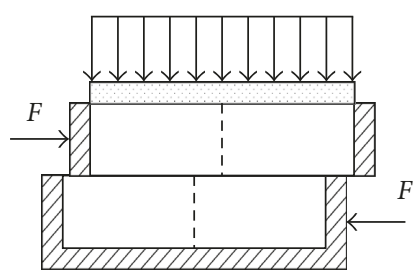

(a)

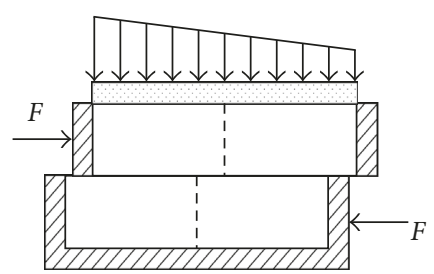

(b)

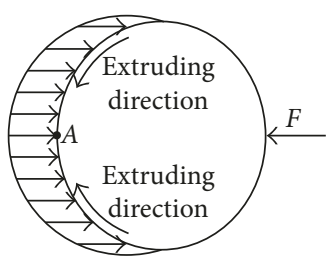

(c)

FIGURE 10: The influence of direct shear experiment on failure modes of discontinuity. (a) Initial state; (b) stress redistribution; (c) stress concentration.

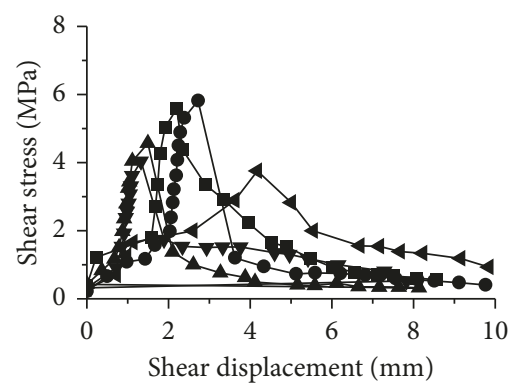

Shear direction

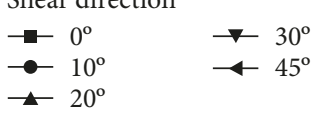

(a)

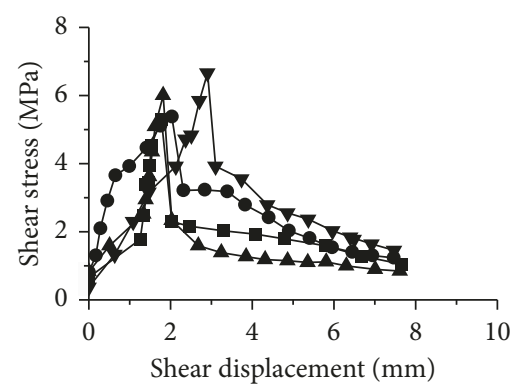

Normal stress

$\rightarrow 0.51 \mathrm{MPa} \rightarrow 2.04 \mathrm{MPa}$

$\multimap 1.02 \mathrm{MPa} \rightarrow 3.06 \mathrm{MPa}$

(d)

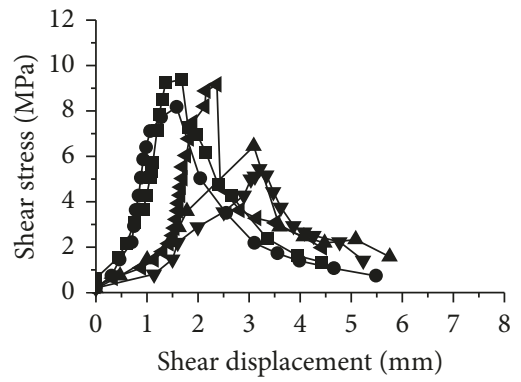

Shear direction

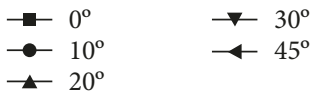

(g)

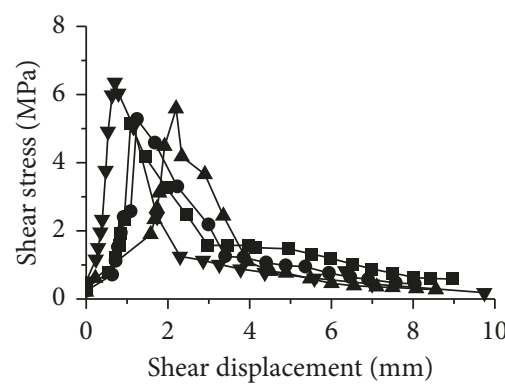

Normal stress

$\rightarrow 0.51 \mathrm{MPa} \longrightarrow 2.04 \mathrm{MPa}$

$\longrightarrow 1.02 \mathrm{MPa} \longrightarrow 3.06 \mathrm{MPa}$

(b)

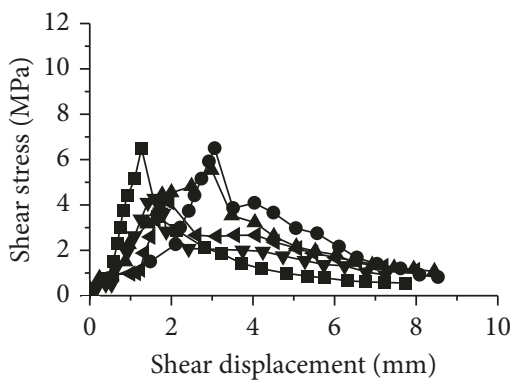

Shear direction

$\rightarrow 0^{\circ} \rightarrow 30^{\circ}$

$\leftarrow 20^{\circ}$

(e)

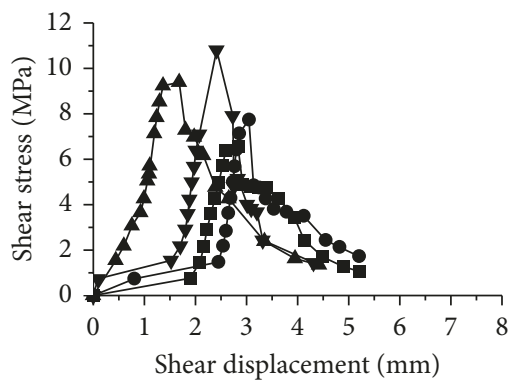

Normal stress

$\rightarrow 0.51 \mathrm{MPa} \longrightarrow 2.04 \mathrm{MPa}$

$\rightarrow 1.02 \mathrm{MPa} \longrightarrow 3.06 \mathrm{MPa}$

(h)

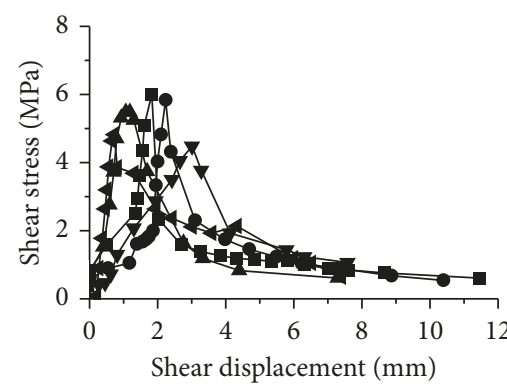

Shear direction

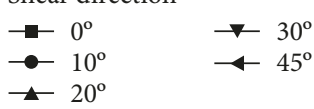

(c)

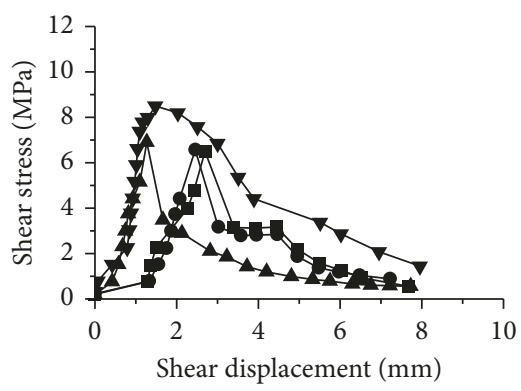

Normal stress

$\rightarrow 0.51 \mathrm{MPa} \longrightarrow 2.04 \mathrm{MPa}$

$\rightarrow 1.02 \mathrm{MPa} \rightarrow 3.06 \mathrm{MPa}$

(f)

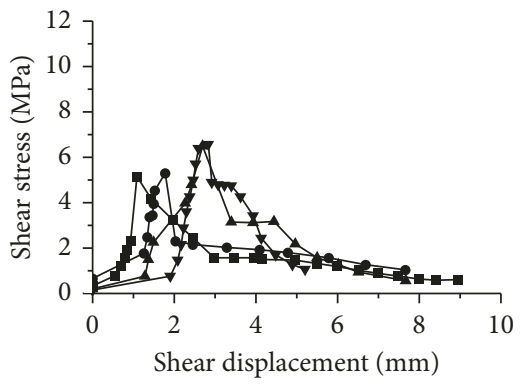

AIA
$\rightarrow-10^{\circ} \rightarrow 30^{\circ}$
$\rightarrow-20^{\circ}$

(i)

FIgURE 11: Continued. 


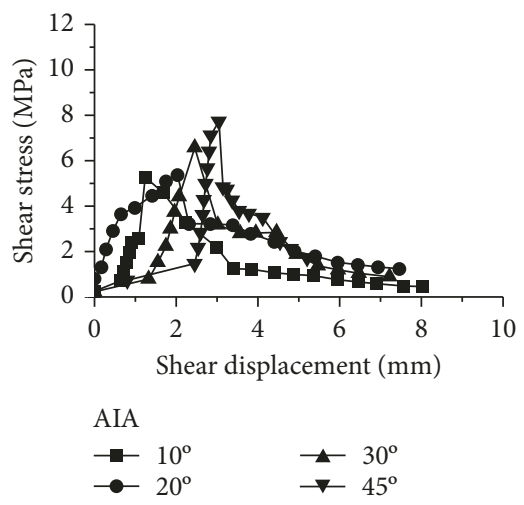

(j)
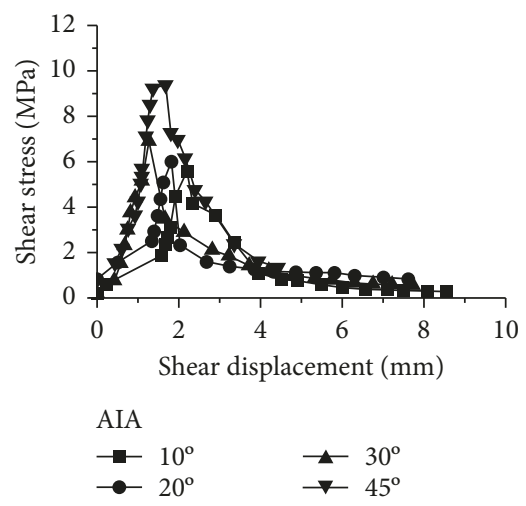

(k)
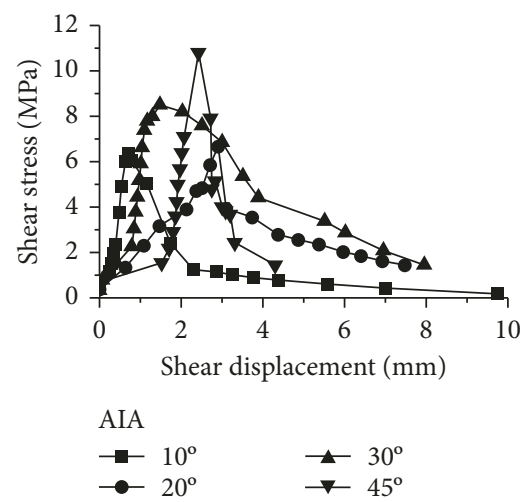

(l)

FIgURE 11: Relation between shear strengths and displacements for the discontinuities with type I. (a) AIA $=10^{\circ}$ and NS $=2.04 \mathrm{MPa}$; (b) $\mathrm{AIA}=10^{\circ}$ and $\mathrm{SD}=0^{\circ}$; (c) $\mathrm{AIA}=20^{\circ}$ and $\mathrm{NS}=2.04 \mathrm{MPa}$; (d) $\mathrm{AIA}=20^{\circ}$ and $\mathrm{SD}=0^{\circ}$; (e) $\mathrm{AIA}=30^{\circ}$ and $\mathrm{NS}=2.04 \mathrm{MPa}$; (f) $\mathrm{AIA}=30^{\circ}$ and $\mathrm{SD}=0^{\circ}$; (g) $\mathrm{AIA}=45^{\circ}$ and $\mathrm{NS}=2.04 \mathrm{MPa}$; (h) $\mathrm{AIA}=45^{\circ}$ and $\mathrm{SD}=0^{\circ}$; (i) $\mathrm{NS}=0.51 \mathrm{MPa}$ and $\mathrm{SD}=0^{\circ}$; (j) $\mathrm{NS}=1.02 \mathrm{MPa}$ and $\mathrm{SD}=0^{\circ}$; (k) $\mathrm{NS}=2.04 \mathrm{MPa}$ and $\mathrm{SD}=0^{\circ}$; (l) $\mathrm{NS}=3.06 \mathrm{MPa}$ and $\mathrm{SD}=0^{\circ}$.

drawbacks of the direct shear instrument. Combined with the experimental results, the failure mechanisms of discontinuity are obtained in the process of the direct shear experiment. In the initial stage, the normal pressure is exerted uniformly on the upper surface of the sample (Figure 10(a)). However, the normal pressure cannot maintain uniform state in the process of the experiment because the action point of normal pressure for the upper shear box and lower shear box cannot maintain uniform, which can lead to nonuniform stress distribution (Figure 10(b)). The rear stress of discontinuity along the shear direction is larger than that of the front of discontinuity which can make the rear part of discontinuity damage easily in the process of the experiment firstly. Under the normal stress influence, shear stress on the surface of discontinuity is not also distributed unequally (Figure 10(c), and the force state of the lower shear box is shown in Figure 10(c)). In the initial stage of shear experiment, stress concentration immediately begins to appear at the rear edge of shear box along the shear direction. And this phenomenon will follow the experimental process. The scope of stress distribution is shown in Figure 10(c). The maximum value of stress appears at the " $\mathrm{A}$ " point in Figure 10(c).

\subsection{Roughness Type I Model and Roughness Type II Model}

3.2.1. Failure Modes of Discontinuity with Jagged Shape for Type I. Figure 11 shows the relation between peak shear stress and shear displacement. The failure modes of discontinuities include brittle failure and ductile or plastic failure under different normal stresses and shear directions. Most of the failure modes are failure by shearing through the asperities. According to the experimental results shown in Figure 11, in addition to the asperity inclination angle and shear direction, the normal stress is a domain influence factor to failure modes of discontinuities. Most of the failure modes for the samples are failure by shearing through the asperities, and the difference in the strength between peak value and residual value is quite significant. Under the normal stress being $2.04 \mathrm{MPa}$, failure by sliding over the asperities of discontinuity appears in parts of the samples. The difference in the strength between peak value and residual value is small. It is about $0.08-0.94 \mathrm{MPa}$. Additionally, the failure mode of discontinuity is main failure by shearing through the asperities when the asperity inclination angle is significant and the normal stress is high. As far as most of the samples are concerned, the maximum differences in the value between peak strength and residual strength will be obtained when the normal stress is $3.06 \mathrm{MPa}$ and the shear direction is $0^{\circ}$. It can also be found in Figure 11 that the residual strengths for most of the samples are far smaller than those of the peak strength. It indicates that the roughness of discontinuity play a vital role to the strength of discontinuity.

Figure 12 shows the relationship between shear directions as well as normal stresses and peak shear strengths under different asperity inclination angles. According to Figure 12, peak shear strength increases gradually with an increase in the asperity inclination angle under deterministic shear direction. However, the maximum shear strength appears when the shear direction is $45^{\circ}$. The stress concentration phenomenon appears when the asperity inclination angle is $45^{\circ}$ and the shear direction is $30^{\circ}$. The peak shear strength decreases gradually with an increase in the shear direction. The change degree of the peak shear strength becomes small when the shear direction is more than $30^{\circ}$. To sum up, the peak shear strength is affected obviously by anisotropy of discontinuity. The whole trends of the curve of peak shear strengths and shear directions are decreasing. And the trends of the curves of peak shear strengths and asperity inclination angles are increasing. The difference of the peak shear strength is small when the asperity inclination angle is less than $30^{\circ}$. The larger asperity inclination angle is, the faster is the decrease ratio of peak shear strength. When the asperity inclination angle is less than $30^{\circ}$, the peak shear strength of sample with the shear direction $10^{\circ}$ to $30^{\circ}$ 

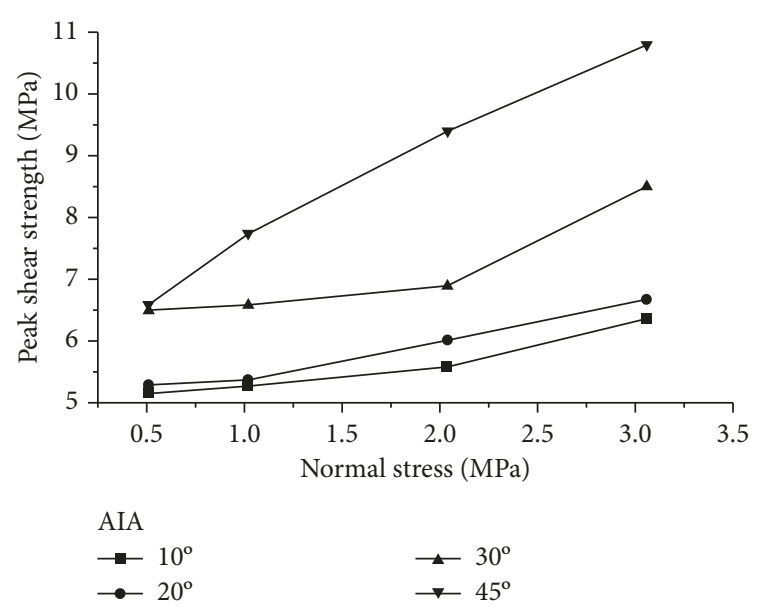

$$
\begin{aligned}
& \longleftarrow 30^{\circ} \\
& \neg \quad 45^{\circ}
\end{aligned}
$$

(a)

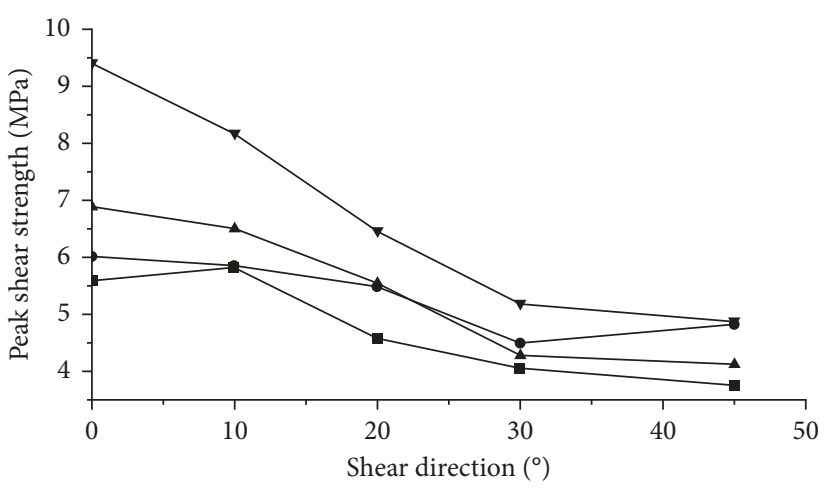

AIA

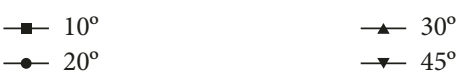

(b)

FIGURE 12: Relationship between shear directions as well as normal stresses and peak shear strengths. (a) Different normal stresses $\left(\mathrm{SD}=0^{\circ}\right)$; (b) different shear directions $(\mathrm{NS}=2.04 \mathrm{MPa})$.

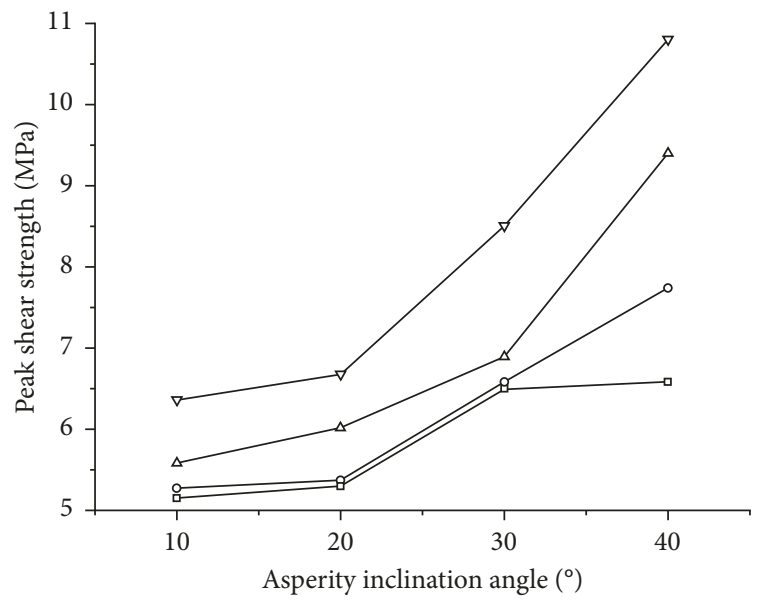

Normal stress

$$
\begin{array}{ll}
\rightarrow 0.51 \mathrm{MPa} & -2.04 \mathrm{MPa} \\
\multimap-1.02 \mathrm{MPa} & \rightarrow-3.06 \mathrm{MPa}
\end{array}
$$$$
\rightarrow \quad 3.06 \mathrm{MPa}
$$

FIGURE 13: Relationship between peak shear strengths and asperity inclination angles under different normal stresses.

decreases fastest. The change ratio of peak shear strength will become small when the shear direction is more than $30^{\circ}$ for different asperity inclination angles. For different shear directions, the peak shear strengths have small difference when the asperity inclination angle is less than $30^{\circ}$.

Figure 13 shows the relationship between peak shear strengths and asperity inclination angles under different normal stresses. Peak shear strength increases gradually with normal stress and asperity inclination angle increases totally. The remarkable changes take place when the normal stress is more than 1.02 $\mathrm{MPa}$. However, the difference in peak shear strength becomes small when the normal stress is less than 1.02, and asperity inclination angles are less than $30^{\circ}$. The main reason is that close integration of discontinuity under small norm stress will cause failure by sliding over the asperities of discontinuity. Meanwhile, under lower asperity inclination angle (such as $10^{\circ}$ and $20^{\circ}$ ), the shear strength of the discontinuity does not show an obvious increasing trend with an increase in normal stress. With the increase in normal stress, the increasing ratio will become large except the asperity inclination angle being more than $30^{\circ}$ and normal stress being $0.51 \mathrm{MPa}$.

3.2.2. Failure Modes of Discontinuities with Type II. Figure 14 shows the relationship between shear strengths and shear displacements of discontinuities with type II. According to Figure 14, the failure modes are failure by shearing through the asperities under different normal stresses and shear directions. The difference in the value between peak strength and residual strength, which is from $1.45 \mathrm{MPa}$ through 8.62 $\mathrm{MPa}$, is very significant for all the samples. The curve of stress and deformation represents an obvious peak value and the residual strength is very small, and those of parts of the samples are near to zero. Based on the experimental results, it can be concluded that the asperity height plays an important role in the failure of discontinuity compared with type I. Another change rule that can be found from Figure 14 is that the peak shear strength will decrease quickly after it reaches the peak value. When the asperity height is less than $4.0 \mathrm{~mm}$, the difference values in shear displacements between the increasing stage and decreasing stage are smaller than those of type I. However, when the asperity height is $8 \mathrm{~mm}$, the $\mathrm{D}$-value is remarkably greater than that of discontinuity with others asperity heights. It indicates the roughness of discontinuity is very vital to peak shear strength. Based on the curve of peak shear strength and shear displacement, after heaves on the surface of discontinuities have been cut, the shear strengths of discontinuities will decrease obviously.

The relationship between peak shear strength and shear direction as well as normal stress under different asperity heights is drawn in Figure 15. According to Figure 15, as far as the discontinuities with deterministic shape are concerned, the shape of the curve presents decreasing trend with an increase in the shear direction. Under the normal stress of 


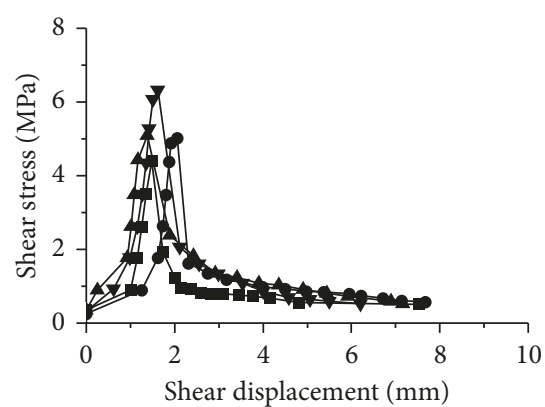

Normal stress

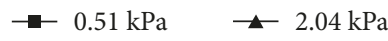

$\multimap-1.02 \mathrm{kPa}$

(a)

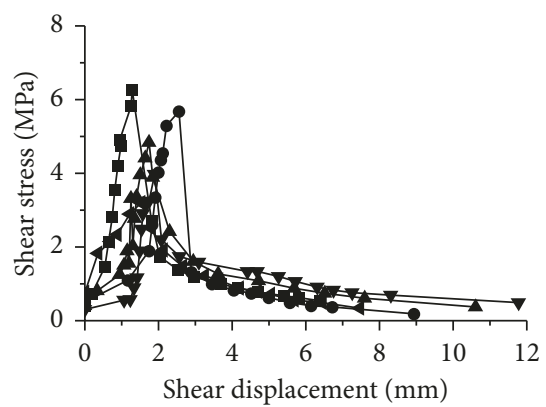

Shear direction

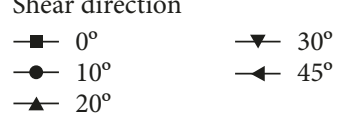

(d)
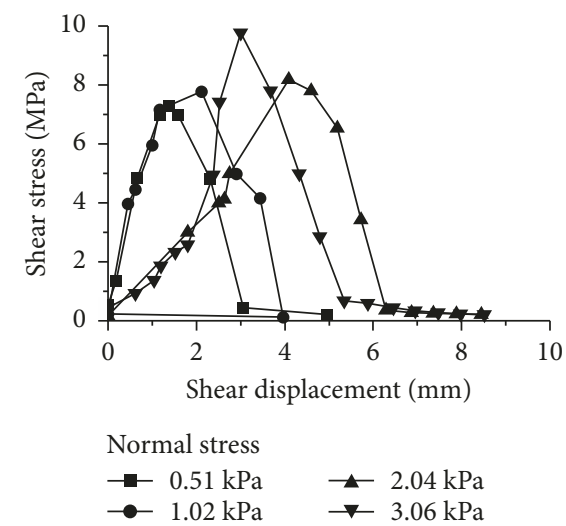

(g)
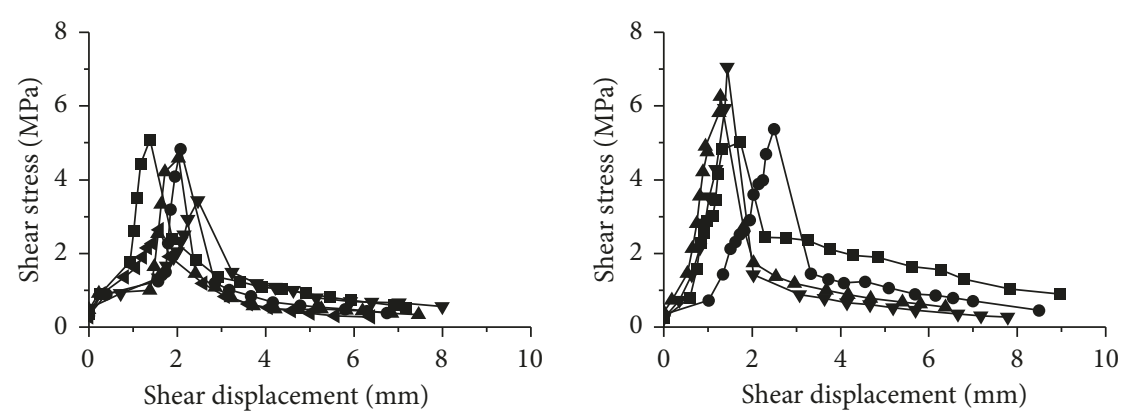

Shear direction

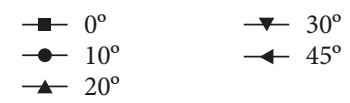

(b)

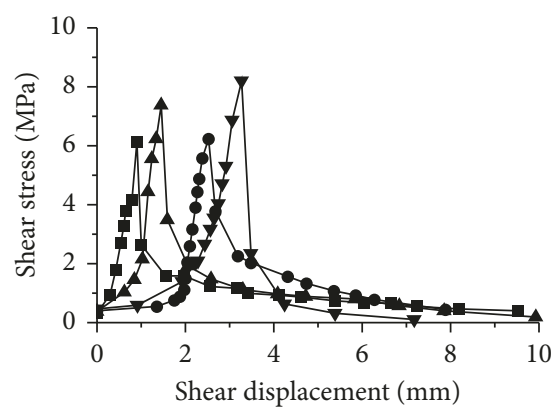

Normal stress

- $0.51 \mathrm{kPa} \longrightarrow 2.04 \mathrm{kPa}$

$\rightarrow 1.02 \mathrm{kPa} \rightarrow 3.06 \mathrm{kPa}$

(e)

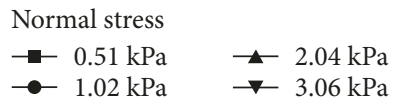

(c)

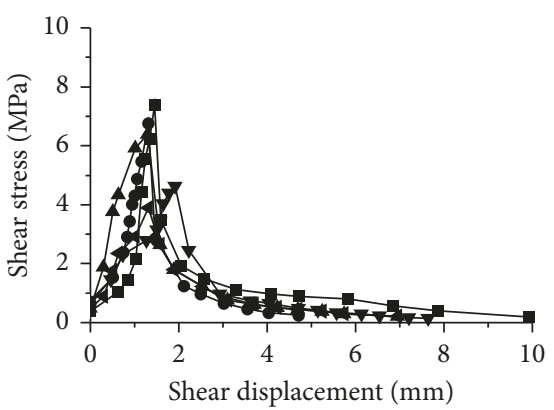

Shear direction

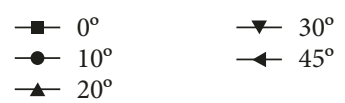

(f)

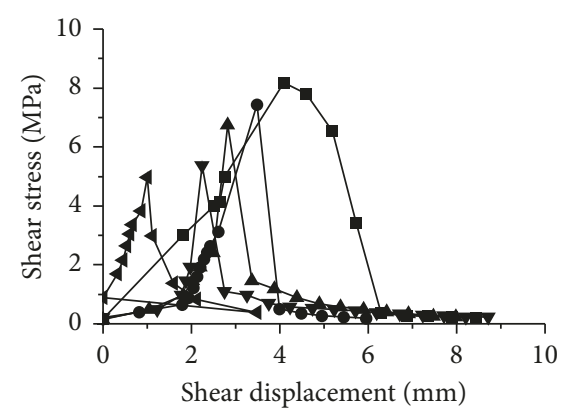

Shear direction

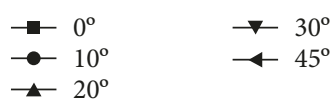

(h)

FIGURE 14: Shear strengths and displacements of discontinuity for type II. (a) $\mathrm{AH}=2 \mathrm{~mm}$ and $\mathrm{SD}=0^{\circ}$; (b) $\mathrm{AH}=2 \mathrm{~mm}$ and NS $=2.04 \mathrm{MPa}$; (c) $\mathrm{AH}=4 \mathrm{~mm}$ and $\mathrm{SD}=0^{\circ}$; (d) $\mathrm{AH}=4 \mathrm{~mm}$ and $\mathrm{NS}=2.04 \mathrm{MPa}$; (e) $\mathrm{AH}=6 \mathrm{~mm}$ and $\mathrm{SD}=0^{\circ}$; (f) $\mathrm{AH}=6 \mathrm{~mm}$ and $\mathrm{NS}=2.04 \mathrm{MPa}$; (g) $\mathrm{AH}=8 \mathrm{~mm}$ and $\mathrm{SD}=0^{\circ}$; (h) $\mathrm{AH}=8 \mathrm{~mm}$ and $\mathrm{NS}=2.04 \mathrm{MPa}$.

2.04 MPa, the influence of shear direction on the shear strength is significant for the same asperity height. Only when the asperity height is $>4 \mathrm{~mm}$ and the shear direction is $20^{\circ} \sim 30^{\circ}$, the peak shear strength shows a sudden decrease. Under the same shear direction, the influence of asperity height on peak shear strength is obviously the same. The curve presents increasing trend when the asperity height is
$2 \mathrm{~cm}$ or $8 \mathrm{~cm}$. The shear strength is significant when the asperity height is from $6 \mathrm{~mm}$ to $8 \mathrm{~mm}$. The change extent will reach the maximum value when the shear direction is $20^{\circ}$. Especially for the asperity height with $8 \mathrm{~mm}$, the peak shear strength emerges a maximum value. This phenomenon can be explained that the asperity height with $8 \mathrm{~cm}$ cannot be damaged easily due to the overheight of the heave on the 


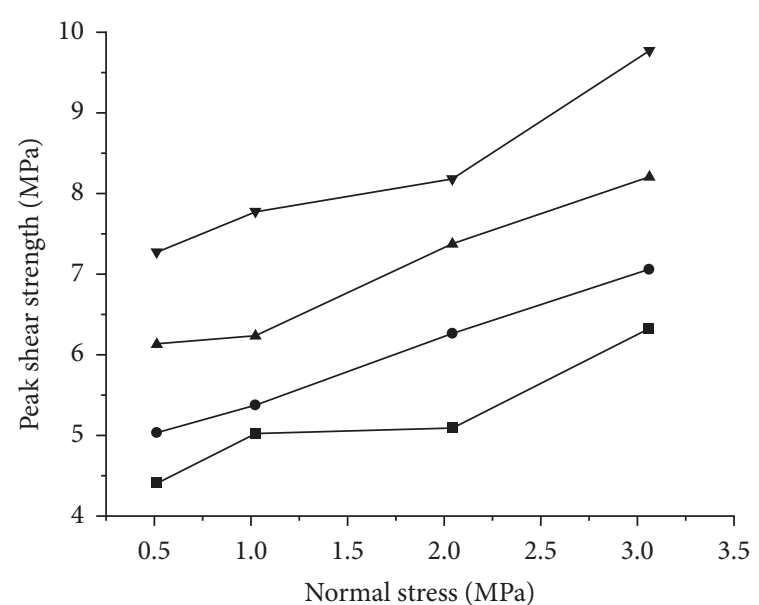

$\mathrm{AH}$

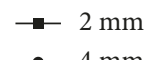

- $4 \mathrm{~mm}$ $\leftarrow 6 \mathrm{~mm}$

$\rightarrow 8 \mathrm{~mm}$

(a)

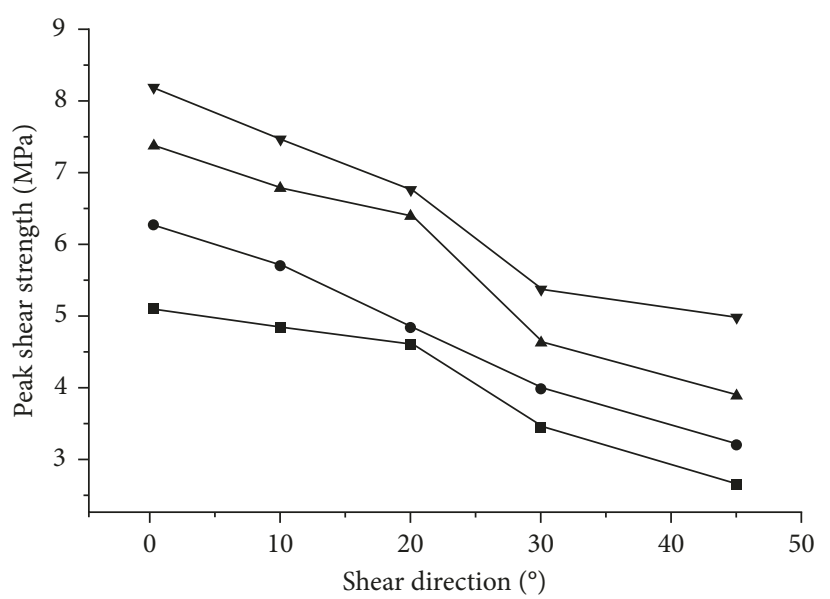

$\mathrm{AH}$

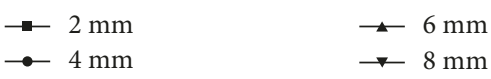

(b)

Figure 15: Relationship between shear direction as well as normal stress and peak shear strength. (a) Different normal stresses $\left(\mathrm{SD}=0^{\circ}\right)$; (b) different asperity heights (NS $=2.04 \mathrm{MPa}$ ).

surface of discontinuity under certain normal stress. Under the deterministic shear direction and normal stress, the peak shear strength of discontinuity increases gradually with an increase in the asperity height. Under the lower normal stress with its value being from $0.51 \mathrm{MPa}$ through $1.02 \mathrm{MPa}$, the shear strength presents small change. However, when the value of normal stress is from 2.04 MPa through $3.06 \mathrm{MPa}$, the shear strength will increase obviously.

Figure 16 shows the relationship between peak shear strengths and asperity heights under different normal stresses. It can be seen from Figure 16 that the peak shear strength with the asperity height being $8 \mathrm{~mm}$ is greater than that of other asperity heights. The larger the normal stress is, the greater the peak shear strength is. Therefore, it can be concluded that the normal stress plays a dominate role to increase the peak shear strength because the significant normal stress will cause close integration of the heaves on the surface of discontinuity which increases the peak shear strength of discontinuity. However, under lower normal stress, the change of peak shear strength is not very remarkable which is can be caused by wearing action on the surface of discontinuity in the process of the shear experiment.

3.3. Roughness Type III Model. The experimental results and shear strength as well as shear displacement curves are shown in Figure 17. The failure modes of quasi-3D discontinuity are main failure by shearing through the asperities under different normal stresses and shear directions. The difference in shear strength between peak value and residual value, which is from 1.69 MPa through 7.44 MPa, is very significant.

According to Figure 17, parts of the samples emerge significant displacements before shear stresses increase with shear displacement. That is to say, the small shear strength presents large displacement. It indicates that the slide along
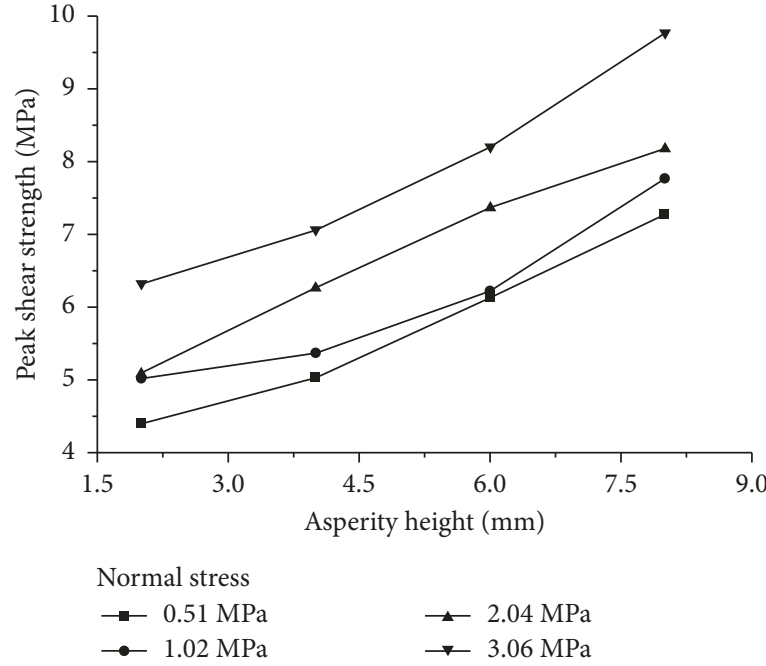

FIGURE 16: Relationship between peak shear strengths and asperity heights under different normal stresses.

the discontinuity occurs when the shear load exerts on the sample. In addition, displacements of some samples are very small between the failure point and initial point except the asperity height being $5-2 \mathrm{~mm}$.

Figure 18(a) shows the relationship between asperity heights and peak shear strengths under different normal stresses. Under lower normal stress being less than 1.0 MPa, peak shear strength changes intensely for different asperity heights. When the normal stress is higher and asperity heights are $5-3 \mathrm{~cm}$ and $5-4 \mathrm{~cm}$, the changes of peak shear strength are small. However, when the asperity heights are $5-4 \mathrm{~cm}$ and $5-5 \mathrm{~cm}$, the peak shear strength presents significant changes, especially for the asperity height being $5-5 \mathrm{~cm}$. For the different asperity heights, the peak shear 


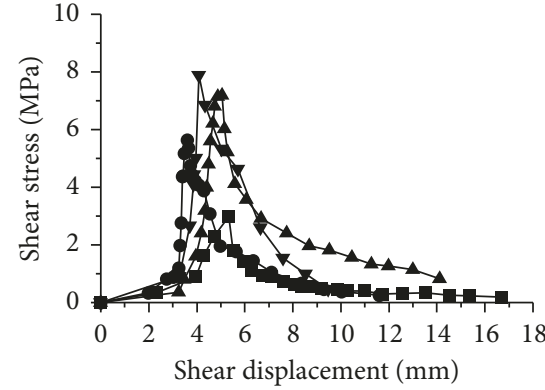

Normal stress

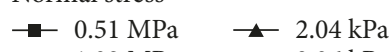

$\longrightarrow 1.02 \mathrm{MPa} \rightarrow 3.06 \mathrm{kPa}$

(a)

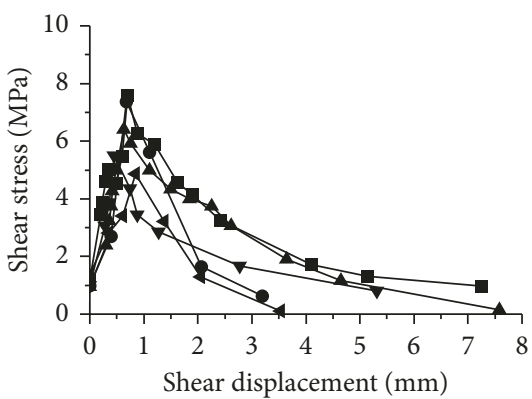

Shear direction

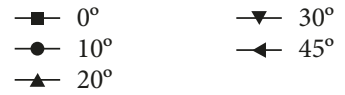

(d)

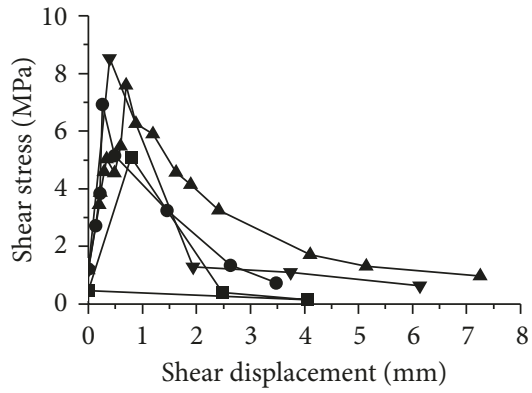

Normal stress

$\rightarrow 0.51 \mathrm{MPa} \rightarrow 2.04 \mathrm{kPa}$

(b)

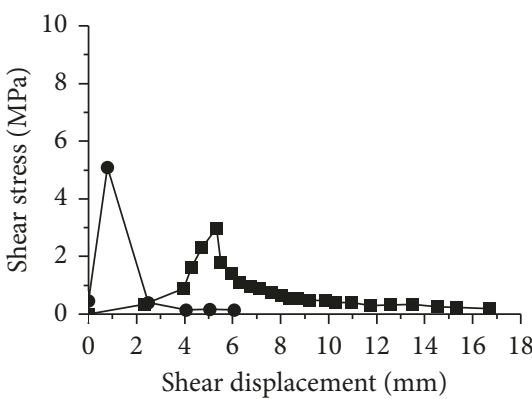

$\mathrm{AH}$

- $5-2 \mathrm{~mm}$

$\rightarrow$ 5-4 mm

(e)

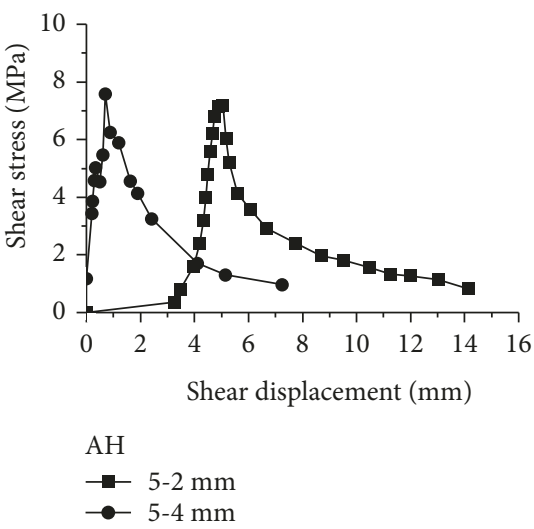

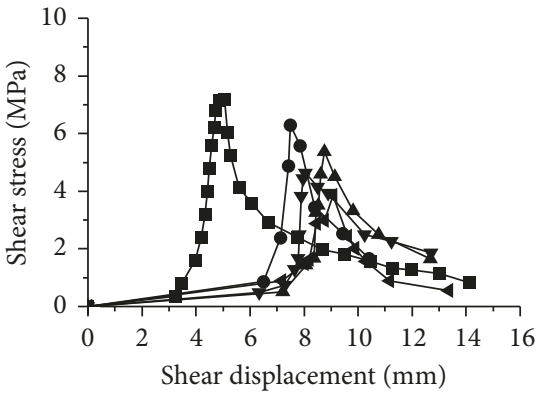

Shear direction

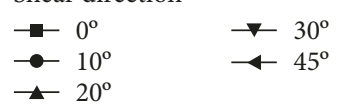

(c)

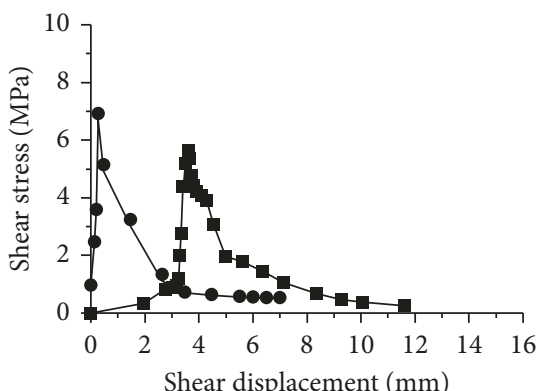

$\mathrm{AH}$

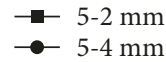

(g)

FIgURE 17: Shear strength and shear displacement of the quasi-3D discontinuity. (a) $\mathrm{AH}=5-2 \mathrm{~mm}$ and $\mathrm{SD}=0^{\circ} ;(\mathrm{b}) \mathrm{AH}=5-2 \mathrm{~mm}$ and $\mathrm{NS}=2.04 \mathrm{MPa}$; (c) $\mathrm{AH}=5-4 \mathrm{~mm}$ and $\mathrm{SD}=0^{\circ}$; (d) $\mathrm{AH}=5-4 \mathrm{~mm}$ and $\mathrm{NS}=2.04 \mathrm{MPa}$; (e) NS $=0.51 \mathrm{MPa}$ and $\mathrm{SD}=00^{\circ}$; (f) $\mathrm{NS}=1.02 \mathrm{MPa}$ and $\mathrm{SD}=0^{\circ} ;(\mathrm{g}) \mathrm{NS}=2.04 \mathrm{MPa}$ and $\mathrm{SD}=0^{\circ}$.

strength increases with an increase in normal stress. The main reason is that the heave on the surface of discontinuity will not be easily damaged and fractured due to significant normal stress which can integrate closely compared to the other asperity heights. Figure 18(b) shows the relationship between shear directions and peak shear strengths under different asperity heights. The peak shear strength decreases with an increase in the angle of shear direction. The peak shear strength of discontinuity with asperity heights being $5-4 \mathrm{~cm}$ and $5-5 \mathrm{~cm}$ is greater than that of discontinuity with asperity heights being $5-2 \mathrm{~cm}$ and $5-3 \mathrm{~cm}$. For the same shear direction, the peak shear strength of discontinuity increases with an increase in the asperity inclination angle. The differences in peak shear strength have small changes when the asperity inclination angle is $<20^{\circ}$ and the asperity heights are $5-2 \mathrm{~cm}$ and $5-3 \mathrm{~cm}$. For all the asperity heights, 

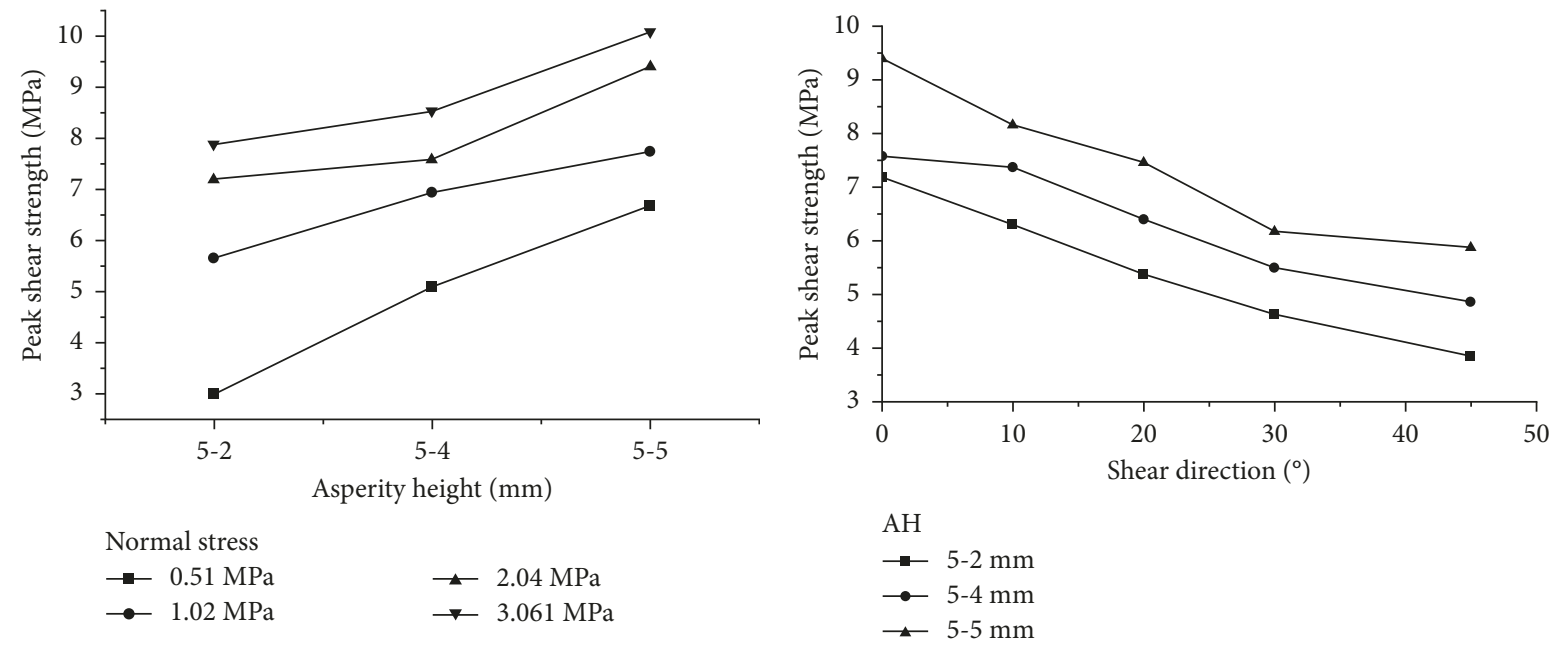

(a)

(b)

FIGURE 18: Relationship between shear directions as well as asperity heights and peak shear strengths. (a) Different asperity heights $(\mathrm{NS}=2.04 \mathrm{MPa})$; (b) different normal stresses $\left(\mathrm{SD}=0^{\circ}\right)$.

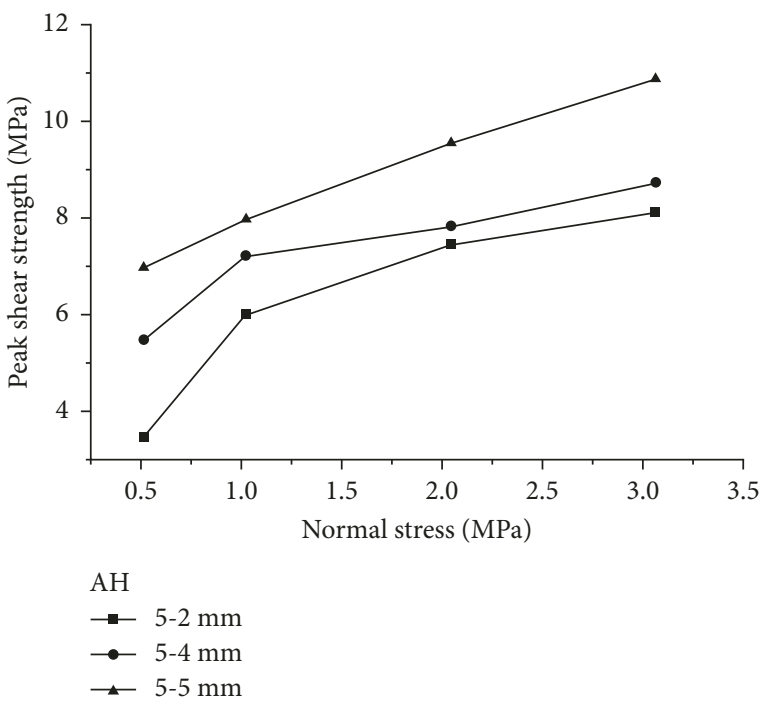

FIgURe 19: The $\tau$ - $\sigma$ curve of the quasi-3D discontinuity under different asperity heights.

the peak shear strength will decrease when the shear direction is $45^{\circ}$. The experimental results are in accordance with that of the theory.

Figure 19 shows the $\tau$ - $\sigma$ curve of the quasi-3D discontinuity under different asperity heights. The change trends of shear stress and normal stress increase totally. The increasing trend of the peak shear strength is high when the normal stress is $<1.02$. There is small change for asperity heights being $5-3 \mathrm{~cm}$ and $5-4 \mathrm{~cm}$. The peak shear strength increases obviously when the asperity heights are $5-2 \mathrm{~cm}$ and $5-5 \mathrm{~cm}$. The reason why the shear strength increases quickly for both of them is that significant difference makes
TABLE 1: Peak shear strengths of natural rough rock joint surfaces under different normal stresses and shear directions.

\begin{tabular}{|c|c|c|c|c|}
\hline \multirow{2}{*}{$\begin{array}{l}\text { Number of } \\
\text { discontinuity }\end{array}$} & \multirow{2}{*}{$\begin{array}{c}\text { Shear } \\
\text { direction, } \theta\left(^{\circ}\right)\end{array}$} & \multicolumn{3}{|c|}{ Normal stress, $\sigma(\mathrm{MPa})$} \\
\hline & & 0.51 & 1.02 & 2.04 \\
\hline \multirow{4}{*}{ A1 } & 0 & 2.18 & 3.19 & 5.45 \\
\hline & 10 & 2.19 & 4.30 & 6.27 \\
\hline & 20 & 8.60 & 12.99 & 16.00 \\
\hline & 30 & 8.00 & 10.64 & 12.25 \\
\hline \multirow{4}{*}{ A2 } & 0 & 10.71 & 12.84 & 14.30 \\
\hline & 10 & 12.04 & 14.32 & 15.07 \\
\hline & 20 & 10.41 & 12.31 & 15.21 \\
\hline & 30 & 11.28 & 13.19 & 15.62 \\
\hline \multirow{4}{*}{ A3 } & 0 & 6.28 & 8.20 & 10.32 \\
\hline & 10 & 14.27 & 16.74 & 17.29 \\
\hline & 20 & 8.06 & 12.56 & 17.30 \\
\hline & 30 & 5.81 & 12.31 & 16.34 \\
\hline \multirow{4}{*}{ A4 } & 0 & 12.68 & 14.89 & 16.26 \\
\hline & 10 & 8.75 & 13.39 & 17.28 \\
\hline & 20 & 6.02 & 9.03 & 14.11 \\
\hline & 30 & 9.06 & 12.02 & 17.80 \\
\hline \multirow{4}{*}{ A5 } & 0 & 2.06 & 4.26 & 7.50 \\
\hline & 10 & 6.12 & 8.99 & 12.74 \\
\hline & 20 & 3.67 & 6.81 & 9.00 \\
\hline & 30 & 7.92 & 10.74 & 15.32 \\
\hline \multirow{4}{*}{ A6 } & 0 & 11.38 & 12.69 & 15.24 \\
\hline & 10 & 10.92 & 13.2 & 16.41 \\
\hline & 20 & 9.82 & 11.94 & 13.79 \\
\hline & 30 & 9.64 & 12.36 & 17.96 \\
\hline \multirow{4}{*}{ A7 } & 0 & 7.04 & 10.85 & 12.02 \\
\hline & 10 & 10.01 & 14.48 & 16.68 \\
\hline & 20 & 11.75 & 14.39 & 16.66 \\
\hline & 30 & 9.74 & 14.03 & 18.36 \\
\hline \multirow{4}{*}{ A8 } & 0 & 5.12 & 7.04 & 8.73 \\
\hline & 10 & 3.21 & 4.22 & 6.38 \\
\hline & 20 & 3.05 & 4.15 & 5.52 \\
\hline & 30 & 4.68 & 5.85 & 6.38 \\
\hline
\end{tabular}



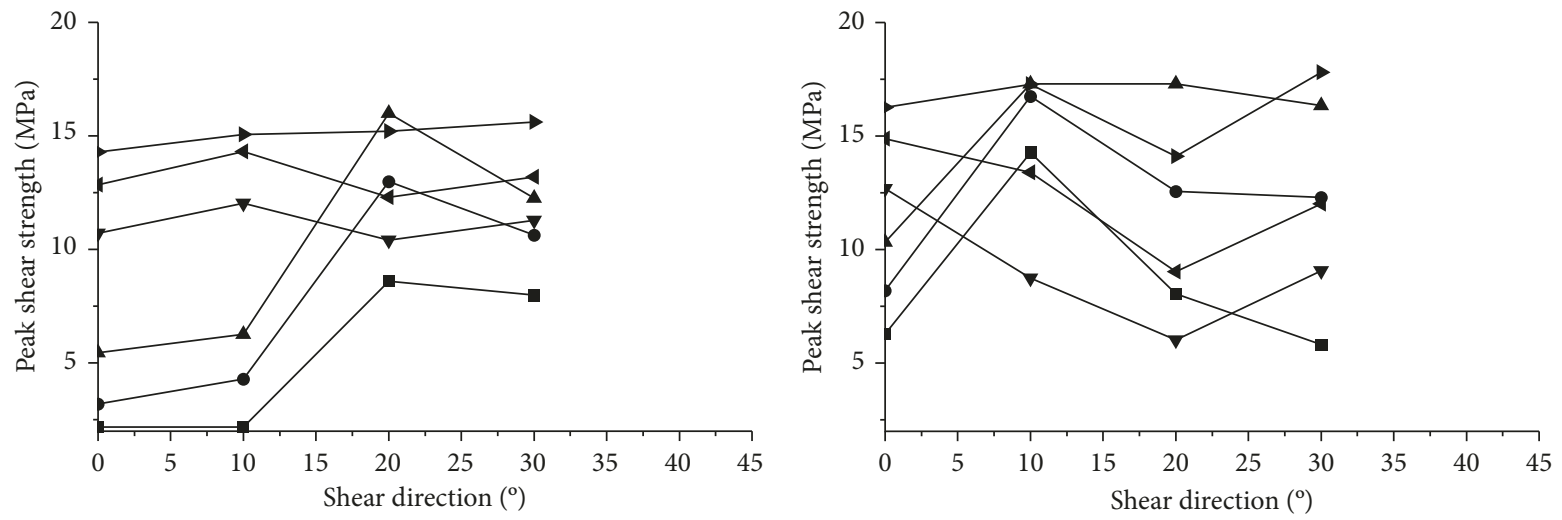

Sample no.-NS

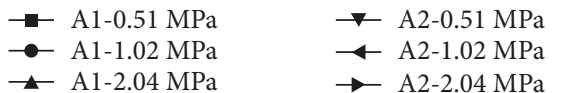

(a)

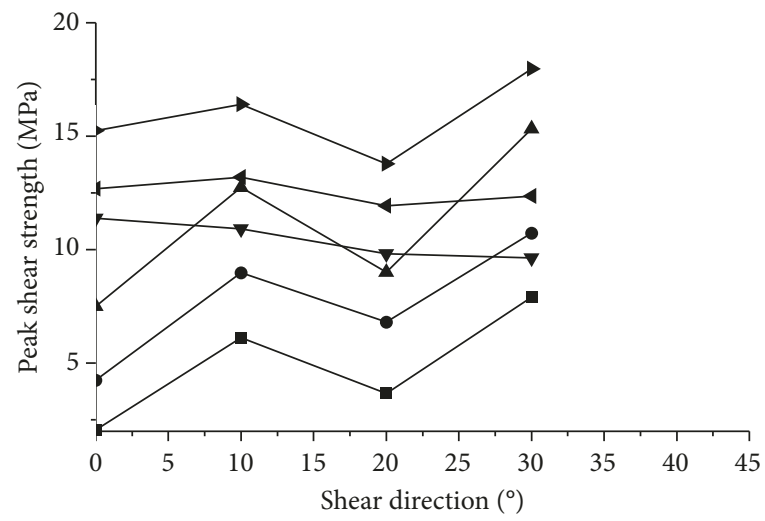

Sample no.-NS

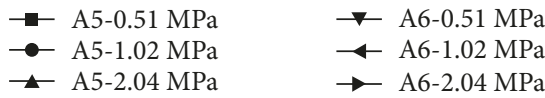

(c)
Sample no.-NS

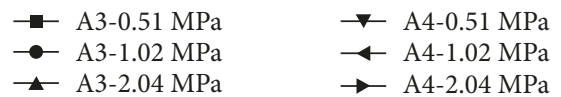

(b)

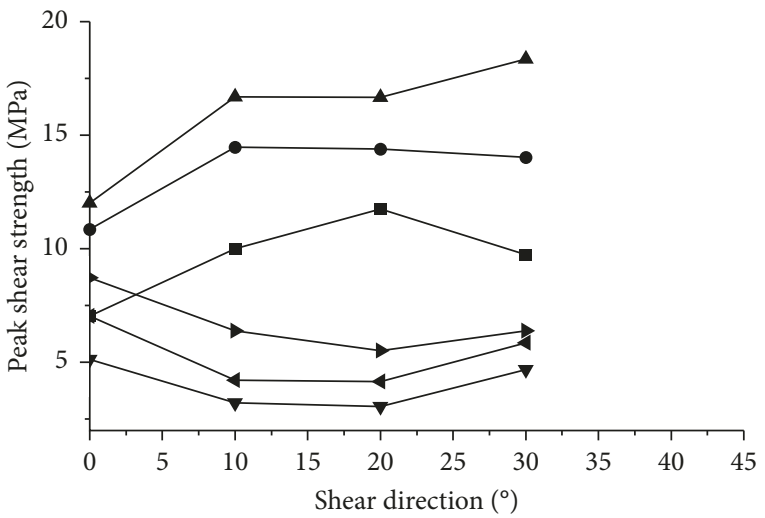

Sample no.-NS

$\rightarrow \mathrm{A} 7-0.51 \mathrm{MPa}$

— A7-2.04 MPa $\checkmark \mathrm{A} 8-0.51 \mathrm{MPa}$
$\leftarrow \mathrm{A} 8-1.02 \mathrm{MPa}$

$\rightarrow$ A8- $2.04 \mathrm{MPa}$

(d)

FIGURE 20: Relationship between peak shear strengths and shear directions for the subsamples of natural rough rock joint surfaces. (a) A1 and A2; (b) A3 and A4; (c) A5 and A6; (d) A7 and A8.

discontinuity integrate closely and causes the strength increase obviously.

3.4. Natural Rough Rock Joint Surface Model. In the experimental process of natural rough rock joint surfaces, eight original site samples of discontinuity and eight sets of concrete subsamples, which every set of the subsamples includes thirty-six samples, are selected to conduct the direct shear experiment. The influence factors include shear direction and normal stress. The shear directions include $0^{\circ}$, $10^{\circ}, 20^{\circ}$, and $30^{\circ}$, respectively, and the normal stresses include $0.51 \mathrm{MPa}, 1.02 \mathrm{MPa}$, and $2.04 \mathrm{MPa}$, respectively. Three samples are used to conduct the direct shear experiment under the same shear direction and normal stress. The every value in Table 1 is obtained by getting the average value of the results based on three samples. Table 1 shows peak shear strengths of natural rough rock joint surfaces under different shear directions and normal stresses.
3.4.1. The Influence of Shear Direction on Peak Shear Strength of Natural Rough Rock Joint Surfaces. According to Table 1 and Figure 20, the influence of shear direction on peak shear strength is very significant, especially for the samples A1, A3, A4, and A5. When the shear direction is $20^{\circ}$, the changes of peak shear strength are remarkable. The samples A2, A6, and A8 have small changes for the peak shear strength. For the same sample, under different normal stresses, the change of peak shear strength is very remarkable due to anisotropy and nonhomogeneity of discontinuity. From Figure 20(d), the sample A8 has small differences with peak shear strength when the shear directions change from $10^{\circ}$ to $30^{\circ}$. The reason is that the surface of discontinuity is more level than that of other discontinuities, and the anisotropy and nonhomogeneity of the discontinuity are not obvious. At the same time, the anisotropy of discontinuities can easily be found in Figure 20 because of their different change laws for different shear directions and the same sample. 


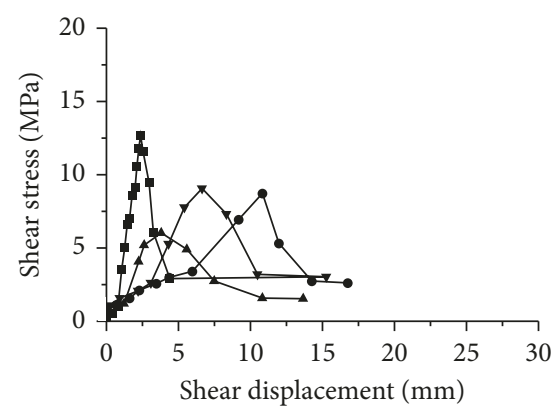

Shear direction

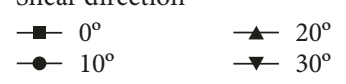

(a)

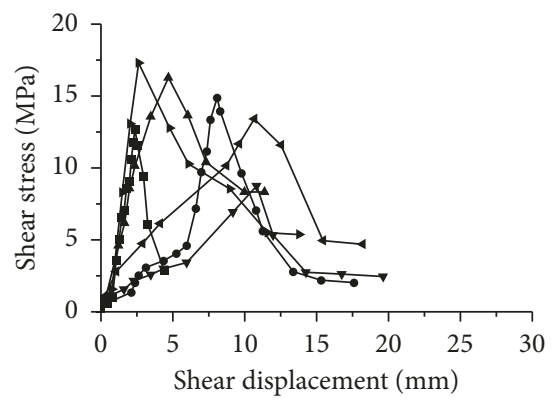

Shear direction (NS)

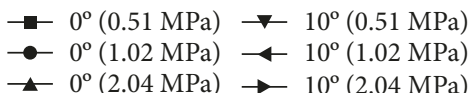

(d)

Shear direction
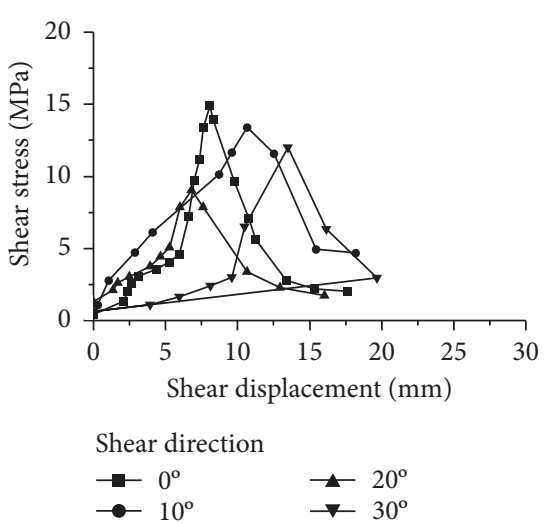

(b)
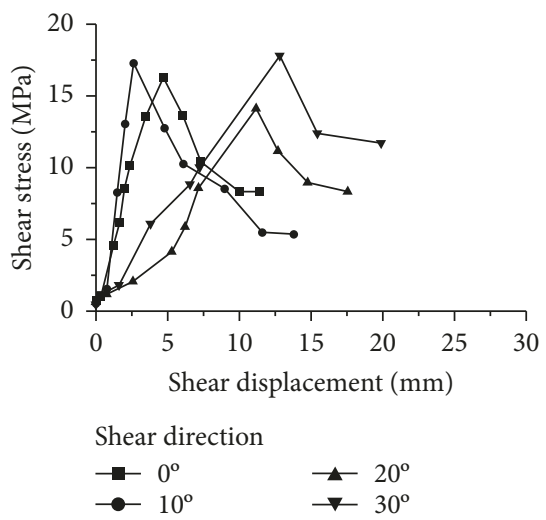

(c)

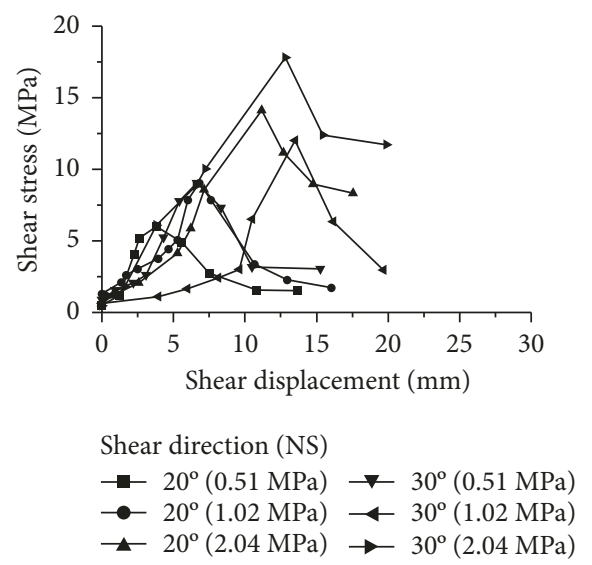

(e)

FIGURE 21: Shear strengths and displacements of the subsamples with natural rough rock joint surface model (A4). (a) NS=0.51 MPa; (b) $\mathrm{NS}=1.02 \mathrm{MPa}$; (c) NS=2.04 MPa; (d) $\mathrm{SD}=0^{\circ}$ and $\mathrm{SD}=10^{\circ}$; (e) $\mathrm{SD}=20^{\circ}$ and $\mathrm{SD}=30^{\circ}$.

\subsubsection{Analysis on Shear Failure Mechanism of Natural Rough Rock Joint Surface}

(1) Subsamples of Natural Rough Rock Joint Surface. Figure 21 shows the shear strengths and shear displacements of subsamples for natural rough rock joint surfaces taking the sample A4 as an example. According to Figure 21 , the failure modes of the subsamples for natural rough rock joint surfaces are main failure by shearing through the asperities, which is brittle failure, under different normal stresses and shear directions. To the sample with failure by shearing through the asperities, the differences in shear strength between peak value and residual value are about from 4.0 $\mathrm{MPa}$ to $14.0 \mathrm{MPa}$. From the experimental results, the failure mode of discontinuity depends on normal stress to a large extent. These capabilities demonstrate that the anisotropy of discontinuity is a crucial factor to its shear strength and failure mode. The deformation law for the sample A4 is completely different. The shear displacement of different shear directions and normal stresses is very significant before it reaches the failure state. Another different characteristic is that the residual strength of the original samples is higher than that of the subsamples.
(2) Original Samples of Natural Rough Rock Joint Surfaces. Table 2 shows the failure modes and shear strengths of the original samples under experimental conditions. According to Table 2, the failure modes of discontinuity with same normal stress are similar. Therefore, normal stress plays an important role for the failure mode of natural rough rock joint surfaces. Under the influence of anisotropy of discontinuity, the failure model might appear failure by sliding over the asperities when the normal stress is higher for the original samples. In the process of the experiment for the original samples, the difference in the value between peak shear strength and residual strength is $0.49-0.72 \mathrm{MPa}$ for failure by sliding over the asperities and 1.33-3.96 MPa for shear failure. For the peak shear strength, the difference in shear strength between the original samples and subsamples is from $1.6 \%$ to $17.45 \%$. The change ratio of residual strength for the original samples and subsamples is greater than that of peak shear strength. It can be concluded that the failure mode of the subsamples is main failure by shearing through the asperities due to the significant difference between peak shear strength and residual strength, while the failure mode for parts of the original samples is failure by sliding over the asperities. This is potentially caused by properties of materials which strength of concrete is less than that of the site. 
TABLE 2: Comparison of failure modes and shear strengths between the original samples and subsamples.

\begin{tabular}{|c|c|c|c|c|c|c|c|c|c|c|c|}
\hline \multirow{2}{*}{ Discontinuity } & \multirow{2}{*}{$\begin{array}{c}\text { Normal stress, } \\
\sigma(\mathrm{MPa})\end{array}$} & \multicolumn{3}{|c|}{ Peak shear strength, $\tau_{p}(\mathrm{MPa})$} & \multicolumn{3}{|c|}{ Residual strength, $\tau_{r}(\mathrm{MPa})$} & \multicolumn{2}{|c|}{$\tau_{p}-\tau_{r}(\mathrm{MPa})$} & \multicolumn{2}{|c|}{ Failure mode } \\
\hline & & (1) & (2) & (3) & (1) & (2) & (3) & (1) & (2) & (1) & (2) \\
\hline A1 & $2.04\left(10^{\circ}\right)$ & 7.47 & 6.27 & $16.1 \%$ & 6.75 & 2.17 & $67.9 \%$ & 0.72 & 4.10 & Wear & Shear \\
\hline $\mathrm{A} 2$ & $1.02\left(10^{\circ}\right)$ & 14.56 & 14.32 & $1.6 \%$ & 10.60 & 3.43 & $67.6 \%$ & 3.96 & 10.89 & Shear & Shear \\
\hline A3 & $0.51\left(0^{\circ}\right)$ & 9.24 & 8.20 & $11.3 \%$ & 7.91 & 6.22 & $21.4 \%$ & 1.33 & 1.98 & Shear & Shear \\
\hline A4 & $2.04\left(10^{\circ}\right)$ & 14.57 & 13.39 & $8.1 \%$ & 12.89 & 5.58 & $56.7 \%$ & 1.68 & 7.81 & Shear & Shear \\
\hline A5 & $0.51\left(10^{\circ}\right)$ & 6.38 & 6.12 & $4.1 \%$ & 5.89 & 3.66 & $37.9 \%$ & 0.49 & 2.46 & Wear & Shear \\
\hline A6 & $0.51\left(30^{\circ}\right)$ & 9.88 & 9.64 & $2.4 \%$ & 6.35 & 5.03 & $20.8 \%$ & 3.53 & 4.61 & Shear & Wear \\
\hline A7 & $0.51\left(0^{\circ}\right)$ & 8.52 & 7.04 & $17.4 \%$ & 4.80 & 3.95 & $17.7 \%$ & 3.72 & 3.09 & Shear & Shear \\
\hline A8 & $2.04\left(0^{\circ}\right)$ & 10.41 & 8.73 & $16.1 \%$ & 7.76 & 2.10 & $72.9 \%$ & 2.65 & 6.63 & Shear & Shear \\
\hline
\end{tabular}

Note: (1) = original sample; (2)= subsample; (3)= change ratio.
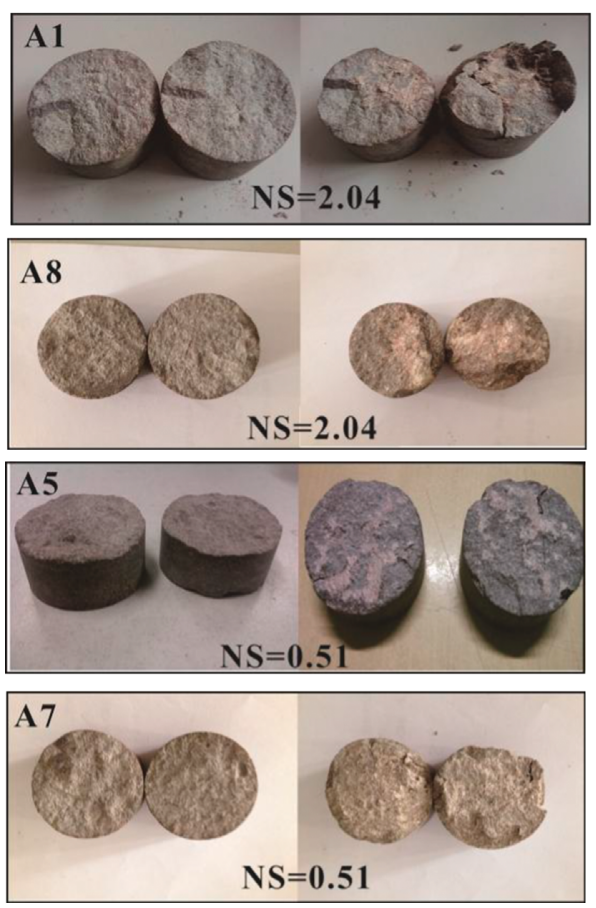

FIGURE 22: Roughness surfaces of the samples before and after the experiment.

Figure 22 shows the roughness surfaces of samples before and after the experiment. Figure 23 shows the relationship between shear strengths and displacements of the original samples for natural rough rock joint surfaces. The peak shear strengths of the original samples are far greater than those of the subsamples. The failure mode is closely related to normal stress and surface topography of discontinuity. The peak shear strength of sample A2 is twice that of sample A3 in the direct shear experiment. It can be explained that the holding-on state between the upper discontinuity and the lower discontinuity is rearranged after the first peak shear strength appears. The heaves on the upper surface of discontinuity keep a tight grip on that of the lower surface of discontinuity which causes the peak shear strength increasing. Meanwhile, the shear strength of the other discontinuities will either slightly decrease or be approximately constant, which makes the failure mode of discontinuity become failure by sliding over the asperities.
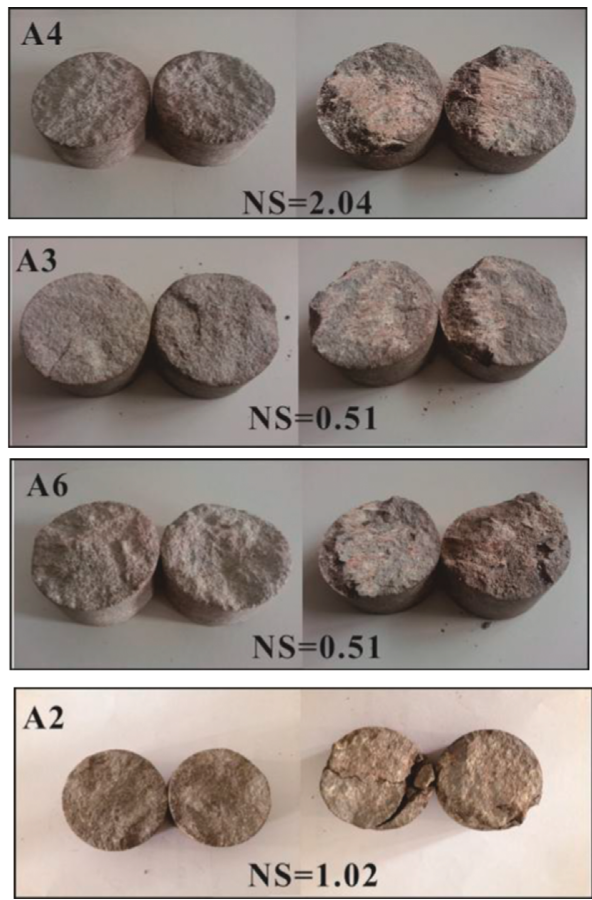

Table 3 shows the area of natural rough rock joint surfaces before and after the experiment. According to Table 3 , the surface area of the discontinuity decreases obviously due to the direct shear experiment. The change ratio for the area of the upper discontinuity is less than that of the lower discontinuity. It can be concluded that the lower discontinuity can easily wear under the influence of the normal stress. Not every discontinuity will be decreased for its surface area after the experiment. Sometimes, it can be increased, for example, the upper surface of the samples A2 and A3. As seen from the samples after the experiment, the surface topography of discontinuity becomes more complex. The reason that caused this phenomenon is dilatancy effect appearing between upper discontinuity and lower discontinuity in the process of the experiment. Hard mineral particles roll in the shear zone which causes more complex surface topography of discontinuity. Therefore, the change ratio of area for the discontinuity depends on surface 


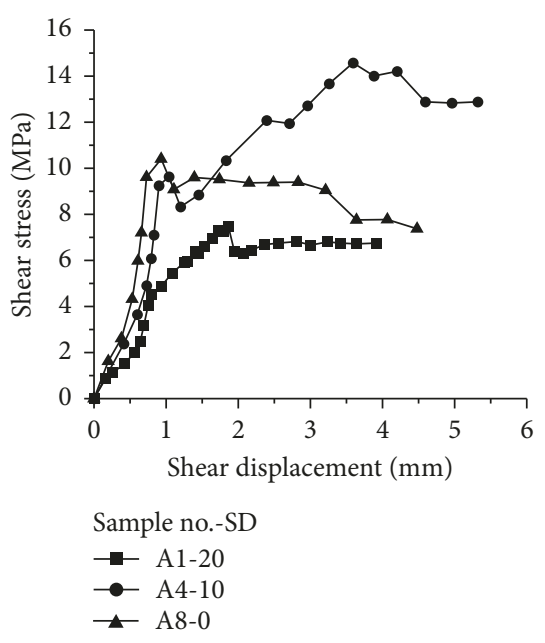

(a)

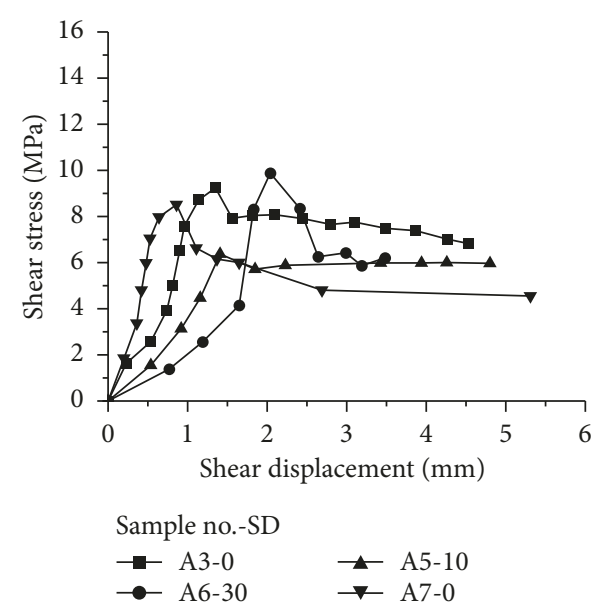

(b)

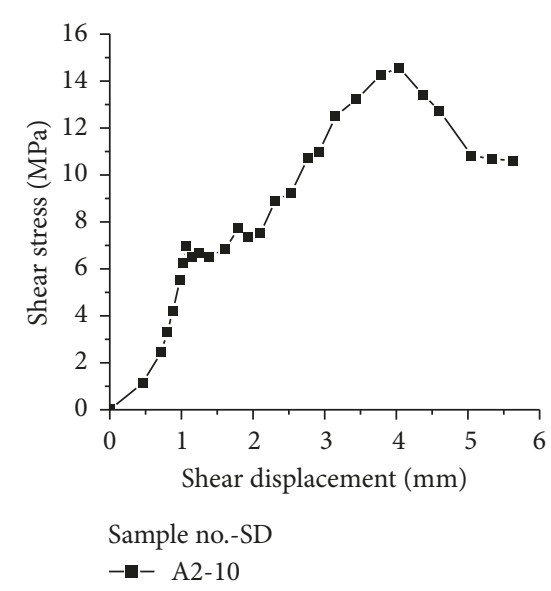

(c)

FIGURE 23: The curve of shear strengths and displacements of the original samples for the natural rough rock joint surface model. (a) NS=2.04; (b) NS=0.51; (c) NS=1.02.

TABLe 3: Areas of natural rough rock joint surface models before and after the experiment.

\begin{tabular}{lccccc}
\hline \multirow{2}{*}{ Discontinuity } & \multicolumn{2}{c}{ Area of the upper discontinuity $\left(\mathrm{mm}^{2}\right)$} & \multicolumn{2}{c}{ Area of the lower discontinuity $\left(\mathrm{mm}{ }^{2}\right)$} \\
& Before test & After test & Change ratio & Before test & After test \\
\hline A1 & 2091.36 & 2022.53 & $3.29 \%$ & 2072.69 & 2018.78 \\
A2 & 2013.01 & 2013.01 & $0.00 \%$ & 2156.83 & 2015.93 \\
A3 & 2028.24 & 2034.52 & $-0.31 \%$ & 2178.09 & 2031.96 \\
A4 & 2149.91 & 1987.12 & $7.57 \%$ & 2153.99 & 1984.53 \\
A5 & 2037.10 & 2033.22 & $0.19 \%$ & 2030.56 & 2005.09 \\
A6 & 2240.31 & 2107.97 & $5.91 \%$ & 2165.84 & 2114.88 \\
A7 & 2075.97 & 2048.28 & $1.33 \%$ & 2146.45 & 2043.26 \\
A8 & 2065.07 & 2033.19 & $1.54 \%$ & 2064.80 & 2035.32 \\
\hline
\end{tabular}

topography, strength of heave on the surface of discontinuity, and particle size of minerals on the surface of discontinuity.

\section{Discussions}

(1) The change trend of peak shear strength for roughness types I and II was similar during model experiments. However, the amplitude of variation for roughness type II was bigger than that of roughness type I. Under different shear directions, the change trend of peak shear strength for roughness types I and II presented "W" shape and the amplitude of variation was similar. The change trend of peak shear strength had good coherence to experimental data under different asperity inclination angles and asperity heights. Compared with roughness types I and II, the change trend of peak shear strength for roughness type III increased first and then decreased with an increase in the normal stress. The peak strength increased with an increase in the asperity height. The amplitude of variation grew by accretion as shear direction.

(2) The experimental results of the natural rough rock joint surface model showed that the peak shear strength of natural rock joint presented different change trends with an increase in the normal stress. For roughness types I, II, and III, the change law of shear strength under different shear directions and normal stresses had obvious variations. In addition, anisotropy of natural joint surface had stronger influence on shear strength of discontinuity than those of aforementioned three types.

(3) Roughness types I, II, and III and natural joint had similar failure modes. However, due to stress concentration at the edge of the samples, the area of discontinuity after the experiment was bigger than that before the experiment for natural joint.

\section{Conclusions}

Rock mass discontinuity plays an important role in the deformation and failure of rock mass. In this study, aiming at the influences of discontinuity roughness on the strength parameters, the model construction and laboratory experiments are conducted based on many factors, such as asperity inclination angle and asperity height. The effects of discontinuity roughness on the mechanical effect of shearing strength are researched. At the same time, the relationship between multidirection shear strength and three-dimensional 
roughness from different shear directions and normal stresses are researched by means of the modeling experiment. The following conclusions can be drawn for the conducted researches:

(1) Standard steel mould and quasi-3D steel mould of discontinuity are designed and manufactured. The modeling samples of two types of discontinuity are constructed by concrete. The mechanical behavior of discontinuity samples with different asperity inclination angles and asperity heights are researched under different shear directions and normal stresses. According to the surface failure topography of different types of discontinuity after the experiment, the shear failure mechanism combined with the corresponding curve of shear stress and shear displacement is studied. It can be found that there are two failure types which are named "failure by shearing through the asperities" and "failure by sliding over the asperities" in discontinuity under different loads, and obvious stress concentration, climbing, and cutting effects appear in the discontinuity in the process of the direct shear experiment.

(2) The discontinuity samples are formed from the rock core in the Lukou airport station of Nanjing City, China. Their 3D roughness is identified based on three-dimensional sensing system (3DSS). The area of natural rough rock joint surfaces is calculated by self-programming software. Finally, the mechanical behavior of the original samples and subsamples of true-3D discontinuity under different shear directions and normal stresses are researched, and at the same time, the failure mechanism of natural rough rock joint surfaces after the experiment is analyzed. The results show that the residual strength of the original samples is higher than that of the subsamples. In addition, the failure mode of the subsample is main failure by shearing through the asperities due to the significant difference between peak shear strength and residual strength, while the failure mode for parts of the original samples is failure by sliding over the asperities. The change ratio of area for the discontinuity after experiment depends on surface topography, strength of heave on the surface of discontinuity, and particle size of minerals on the surface of discontinuity.

\section{Conflicts of Interest}

The authors declare that there are no conflicts of interest.

\section{Acknowledgments}

This research is financially supported by the Natural Science Foundation of China (Grant nos. 41672258, 41102162, and 41472241) and Natural Science Foundation of Jiangsu Province, China (Grant no. BK20141415). The authors gratefully acknowledge Wei Shi and Yinlong Han in School of Earth Sciences and Engineering, Hohai University, China, for their contribution to the laboratory experiment.

\section{References}

[1] N. Barton and S. Bandism, "Review of predictive capabilities of JRC-JCS model in engineering practice," Publikasjoner, vol. 182, pp. 1-8, 1991.

[2] D. K. Ghosh and M. Srivastava, "Point-load strength: an index for classification of rock material," Bulletin of Engineering Geology and the Environment, vol. 44, no. 1, pp. 27-33, 1991.

[3] P. S. Andrade and A. A. Saraiva, "Estimating the joint roughness coefficient of discontinuities found in metamorphic rocks," Bulletin of Engineering Geology and the Environment, vol. 67, no. 3, pp. 425-434, 2008.

[4] A. Basu, D. A. Mishra, and K. Roychowdhury, "Rock failure modes under uniaxial compression, Brazilian, and point load tests," Bulletin of Engineering Geology and the Environment, vol. 72, no. 3-4, pp. 457-475, 2013.

[5] P. H. S. W. Kulatilake, J. Um, and G. Pan, "Requirements for accurate quantification of self-affine roughness profiles using variogram method," International Journal of Solids and Structures, vol. 35, no. 31-32, pp. 4167-4189, 1998.

[6] K. Develi, T. Babadagli, and C. Comlekci, "A new computercontrolled surface-scanning device for measurement of fracture surface roughness," Computers and Geosciences, vol. 27, no. 3, pp. 265-277, 2001.

[7] Q. Feng, N. Fardin, L. Jing, and O. Stephansson, "A new method for in-situ non-contact roughness measurement of large rock fracture surfaces," Rock Mechanics and Rock Engineering, vol. 36, no. 1, pp. 3-25, 2003.

[8] N. Fardin, Q. Feng, and O. Stephansson, "Application of a new in situ 3D laser scanner to study the scale effect on the rock joint surface roughness," International Journal Rock Mechanics and Mining Sciences, vol. 41, no. 2, pp. 329-335, 2004.

[9] S. L. Huang, S. M. Oelfke, and R. C. Speck, "Applicability of fractal characterization and modelling to rock joint profiles," International Journal of Rock Mechanics and Mining Science and Geomechanics Abstracts, vol. 29, no. 2, pp. 89-98, 1992.

[10] N. E. Odling, "Natural fracture profiles, fractal dimension and joint roughness coefficient," Rock Mechanics and Rock Engineering, vol. 27, no. 3, pp. 135-153, 1994.

[11] P. H. S. W. Kulatilake, P. Balasingam, J. Park, and R. Morgan, "Natural rock joint roughness quantification through fractal techniques," Geotechnical and Geological Engineering, vol. 24, no. 5, pp. 1181-1202, 2006.

[12] P. Fortsakis, K. Nikas, V. Marinos, and P. Marinos, "Anisotropic behaviour of stratified rock masses in tunneling," Engineering Geology, vol. 141-142, pp. 74-83, 2012.

[13] L. Peyras, P. Rivard, P. Breul, A. Millet, and G. Ballivy, "Characterization of rock discontinuity openings using acoustic wave amplitude-application to a metamorphic rock mass," Engineering Geology, vol. 193, pp. 402-411, 2015.

[14] A. L. Che, H. K. Yang, B. Wang, and X. R. Ge, "Wave propagations through jointed rock masses and their effects on the stability of slopes," Engineering Geology, vol. 201, pp. 45-56, 2016.

[15] S. M. Hsiung, A. Ghosh, M. P. Ahola, and A. H. Chowdhury, "Assessment of conventional methodologies for joint roughness coefficient determination," International Journal of Rock Mechanics and Mining Science and Geomechanics Abstracts, vol. 30, no. 7, pp. 825-829, 1993. 
[16] T. Belem, F. H. Etienne, and M. Souley, "Quantitative parameters for rock joint surface roughness," Rock Mechanics and Rock Engineering, vol. 33, no. 4, pp. 217-242, 2000.

[17] E. S. Hong, J. S. Lee, and I. M. Lee, "Underestimation of roughness in rough rock joints," International Journal for Numerical and Analytical Methods in Geomechanics, vol. 32, no. 11, pp. 1385-1403, 2008.

[18] Z. J. Wu and L. N. Y. Wong, "Modeling cracking behavior of rock mass containing inclusions using the enriched numerical manifold method," Engineering Geology, vol. 162, pp. 1-13, 2013.

[19] A. Kayabasi, N. Yesiloglu-Gultekin, and C. Gokceoglu, "Use of non-linear prediction tools to assess rock mass permeability using," Engineering Geology, vol. 185, pp. 1-9, 2015.

[20] N. Barton, "Review of a new shear strength criterion for rock joints," Engineering Geology, vol. 7, pp. 1-54, 1988.

[21] G. Grasselli, J. Wirth, and P. Egger, "Quantitative threedimensional description of rough surface and parameter evolution with shearing," International Journal Rock Mechanics and Mining Sciences, vol. 39, no. 6, pp. 789-800, 2002.

[22] A. J. Riquelme, A. Abelian, and R. Tomas, "Discontinuity spacing analysis in rock masses using 3D point clouds," Engineering Geology, vol. 195, pp. 185-195, 2015.

[23] T. Koyama, N. Fardin, L. Jing, and O. Stephansson, "Numerical simulation of shear induced flow anisotropy and scale dependent aperture and transmissivity evolutions of fracture replicas," International Journal of Rock Mechanics and Mining Sciences, vol. 43, no. 1, pp. 89-106, 2006.

[24] Y. J. Jiang, B. Li, and Y. Tanabashi, "Estimating the relation between surface roughness and mechanical properties of rock joints," International Journal of Rock Mechanics and Mining Sciences, vol. 43, no. 6, pp. 837-846, 2006. 


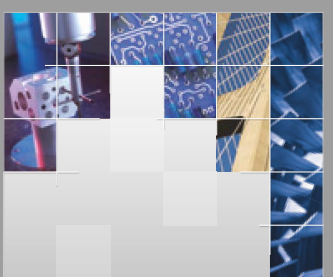

\section{Enfincering}
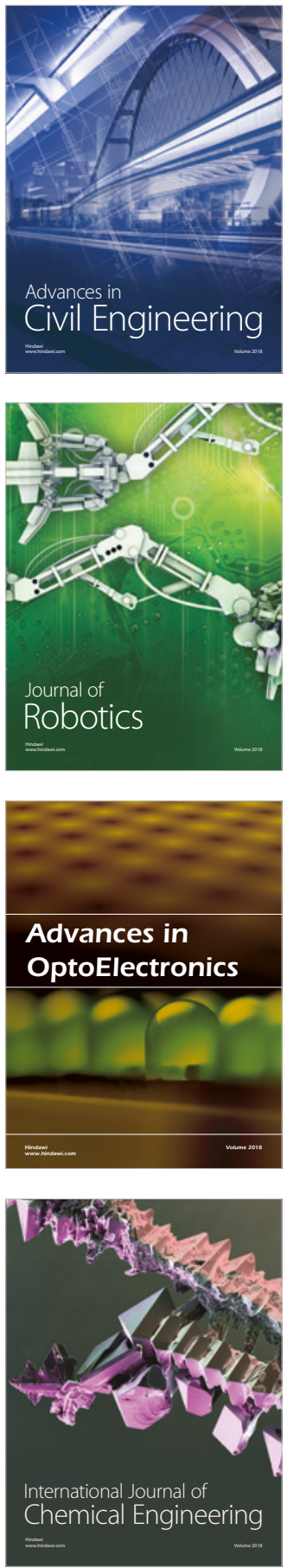

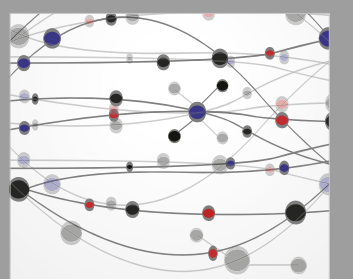

\section{Rotating \\ Machinery}

The Scientific World Journal

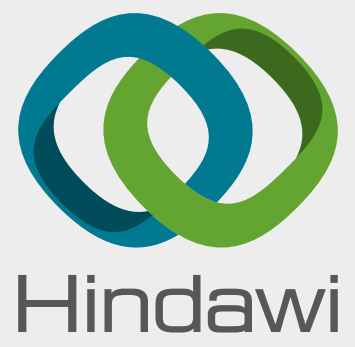

Submit your manuscripts at

www.hindawi.com
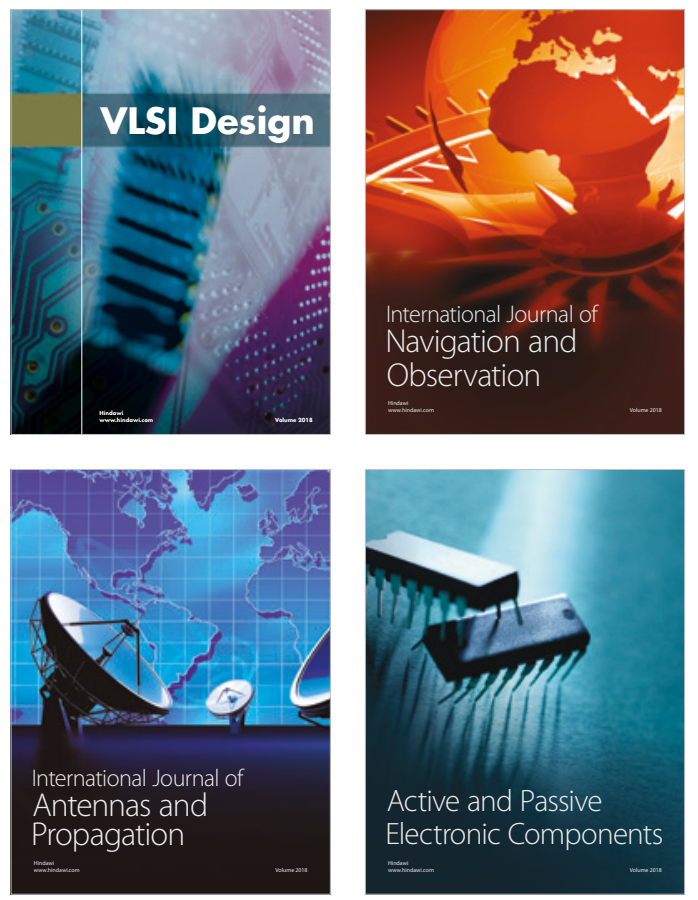
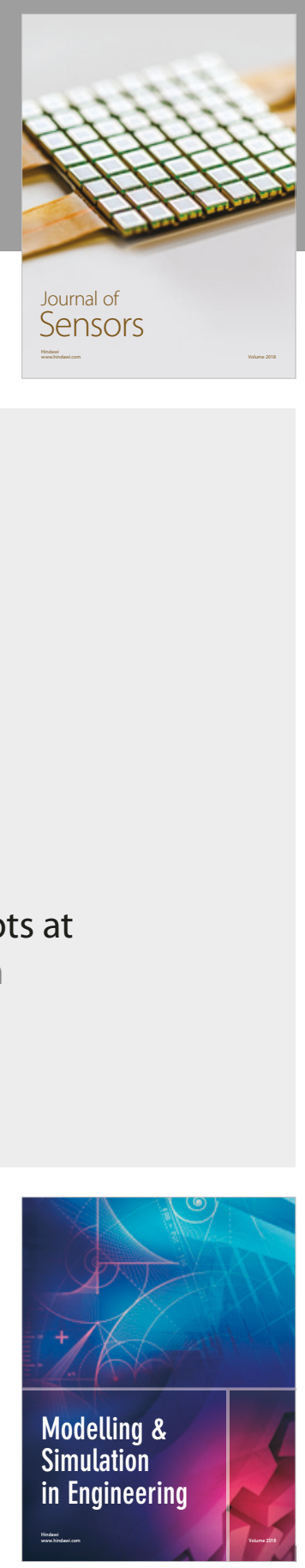

\section{Advances \\ Multimedia}
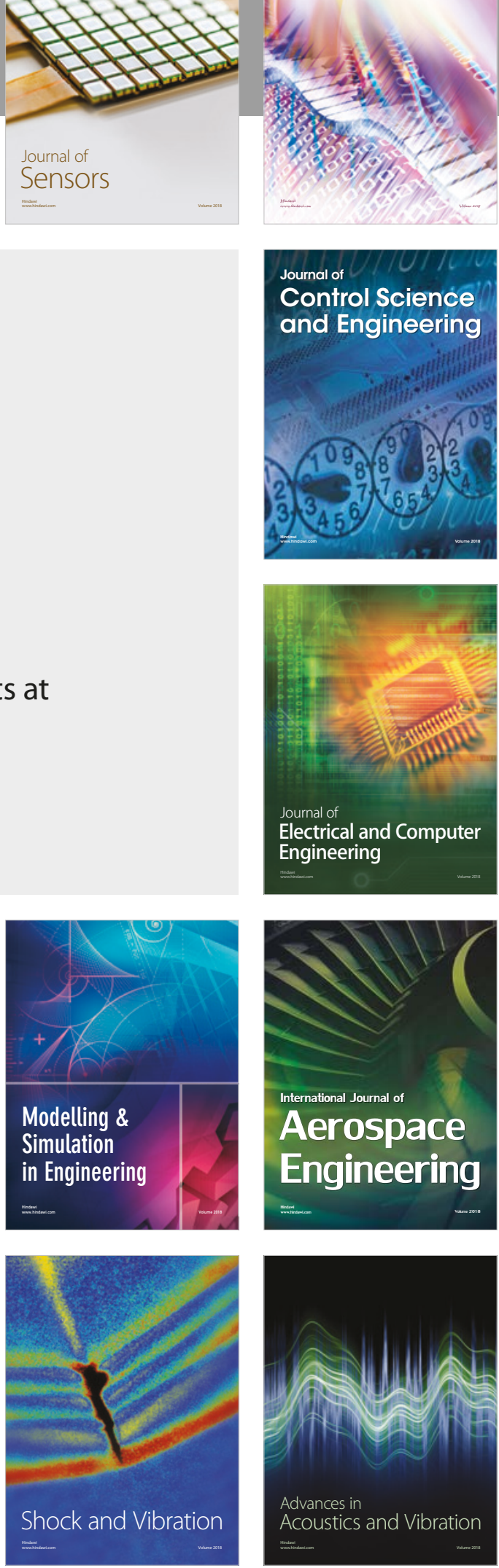